\title{
Role of Estrogen and Other Sex Hormones in Brain Aging. Neuroprotection and DNA Repair
}

\author{
Sandra Zárate ${ }^{1,2}$, Tinna Stevnsner ${ }^{3}$ and Ricardo Gredilla ${ }^{4 *}$ \\ ${ }^{1}$ Instituto de Investigaciones Biomédicas (INBIOMED, UBA-CONICET), Facultad de Medicina, Universidad de Buenos Aires, \\ Buenos Aires, Argentina, ²Departamento de Histología, Embriología, Biología Celular y Genética, Facultad de Medicina, \\ Universidad de Buenos Aires, Buenos Aires, Argentina, ${ }^{3}$ Danish Center for Molecular Gerontology and Danish Aging \\ Research Center, Department of Molecular Biology and Genetics, University of Aarhus, Aarhus, Denmark, ${ }^{4}$ Department of \\ Physiology, Faculty of Medicine, Complutense University, Madrid, Spain
}

\section{OPEN ACCESS}

Edited by:

Isabel Varela-Nieto, Consejo Superior de Investigaciones Cientificas (CSIC), Spain

Reviewed by:

Christian J. Pike, University of Southern California, United States Jose L. Labandeira-Garcia, Universidade de Santiago de Compostela, Spain

*Correspondence: Ricardo Gredilla gredilla@ucm.es

Received: 19 October 2017 Accepted: 14 December 2017 Published: 22 December 2017

Citation: Zárate S, Stevnsner T and Gredilla R (2017) Role of Estrogen and Other Sex Hormones in Brain Aging. Neuroprotection and DNA Repair. Front. Aging Neurosci. 9:430. doi: 10.3389/fnagi.2017.00430
Aging is an inevitable biological process characterized by a progressive decline in physiological function and increased susceptibility to disease. The detrimental effects of aging are observed in all tissues, the brain being the most important one due to its main role in the homeostasis of the organism. As our knowledge about the underlying mechanisms of brain aging increases, potential approaches to preserve brain function rise significantly. Accumulating evidence suggests that loss of genomic maintenance may contribute to aging, especially in the central nervous system (CNS) owing to its low DNA repair capacity. Sex hormones, particularly estrogens, possess potent antioxidant properties and play important roles in maintaining normal reproductive and non-reproductive functions. They exert neuroprotective actions and their loss during aging and natural or surgical menopause is associated with mitochondrial dysfunction, neuroinflammation, synaptic decline, cognitive impairment and increased risk of age-related disorders. Moreover, loss of sex hormones has been suggested to promote an accelerated aging phenotype eventually leading to the development of brain hypometabolism, a feature often observed in menopausal women and prodromal Alzheimer's disease (AD). Although data on the relation between sex hormones and DNA repair mechanisms in the brain is still limited, various investigations have linked sex hormone levels with different DNA repair enzymes. Here, we review estrogen anti-aging and neuroprotective mechanisms, which are currently an area of intense study, together with the effect they may have on the DNA repair capacity in the brain.

Keywords: brain aging, neuroprotection, sex hormones, estrogen, DNA repair, mitochondria

\section{INTRODUCTION}

The world's population is aging. Life expectancy at birth has increased by 6 years worldwide in the last 3 decades, and in 2050 the proportion of old adults over 60 years is estimated to reach $22 \%$ worldwide. Such an increase has a direct consequence: a rise in the incidence of age-related diseases, in particular neurodegeneration. According to different organizations like the World Health Organization (WHO), neurodegenerative disorders are, together with cardiovascular diseases, the main causes of death in western countries. More than $20 \%$ of adults aged 60 and over develop neurological disorders, dementia being the most common one. WHO estimates that around 47 million people suffer from this disorder, with nearly 10 million new cases every year. 
Thus, it is estimated that the total number of people with dementia will increase to near 75 million in 2030 and 132 million by 2050 worldwide. Alzheimer's disease (AD) is the most common cause of dementia, contributing to $60 \%-70 \%$ of cases. Although a relationship between the development of cognitive impairment and life-style-related risk factors, such as obesity, tobacco and alcohol use has been reported, age is still the strongest risk factor for dementia and other neurodegenerative disorders (World Health Statistics, 2017).

Despite aging globally affects both male and female animals from all species, including humans, various studies have stressed that sex differences exist. Thus, females have longer life expectancies than males in mammals, and that is also the case for women vs. men in most developed countries (Promislow, 1991; Schroots et al., 1999). Since such higher life expectancy is not exclusive for humans, it cannot be attributed only to socioeconomical factors but rather reflects specific biological characteristics of both sexes. Similarly, the incidence of various age-related neurodegenerative diseases shows a sex-dependency. Thus, Parkinson's disease (PD) has a higher prevalence and earlier onset in males compared to females (Gillies et al., 2014). Likewise, men over the age of 40 have smaller volumes in different brain areas, including the hippocampus (Coffey et al., 1998; Jack et al., 2015) and worse memory performance than age-matched women (Jack et al., 2015). On the other hand, post-menopausal women have a higher prevalence of $\mathrm{AD}$ than men, as well as a faster cognition decline after disease onset (Li and Singh, 2014; Zagni et al., 2016). The factors promoting the longer lifespan in women vs. men as well as sex dimorphisms in brain aging and neurodegenerative diseases are not fully understood. The positive effects of estrogen on different cellular processes, such as reactive oxygen species (ROS) production and antioxidant defense, cardiovascular protection, immune competence and telomere maintenance have been well recognized to account, at least in part, for women's longer lifespan (Regan and Partridge, 2013; Austad and Fischer, 2016). However, it may seem paradoxical that women still live longer than men long after hormonal loss due to menopause and consequently long after having benefited from the protective effects of estrogens. Interestingly, a positive correlation between later age at menopause or longer reproductive lifespan with longevity has been recently reported (Shadyab et al., 2017). That suggests that lifetime cumulative exposure to estrogenic stimulation throughout fertile life could exert long-lasting effects and account for such sex dimorphism in longevity. This exposure would also affect brain aging and neurodegenerative processes. Altogether, the above mentioned sex differences suggest that taking sex into account as a biological variable might be critical when approaching therapies to treat neurodenegerative diseases or to delay brain aging (Young and Pfaff, 2014; May, 2016).

\section{Neuroprotective Effects of Sex Hormones}

As mentioned above, one factor that is believed to play an important role in the sex differences observed in brain aging and neurodegeneration is sex hormone levels, in particular estrogen. It is well known that estrogen receptors (ERs) are widely distributed in the brain (Hara et al., 2015), having important regulatory function on different processes such as cognition, anxiety, body temperature, feeding and sexual behavior (Do Rego et al., 2009). The neuroprotective effect of estrogen has been stressed by several investigations. Epidemiological studies suggest that late symptom onset of PD in women may be related to such neuroprotective effect (Saunders-Pullman et al., 1999; Rocca et al., 2008; Kowal et al., 2013). It has also been suggested that the reduced concentration of sex steroid hormones after menopause may be responsible for the higher prevalence and greater severity of AD in women than men (Tang et al., 1996; Brann et al., 2007; Li and Singh, 2014). Moreover, in support of the neuroprotective effect of sex steroids, hormone replacement therapy (HRT) has been shown to have beneficial effects on different animal models (Borrás et al., 2003; Ding et al., 2013; Lu et al., 2018). Clinical data also suggest that HRT may have an effect in humans on neurodegenerative diseases such as $\mathrm{AD}$ (Li and Singh, 2014), PD and other age-related brain diseases like stroke (Brann et al., 2007), although concerns about its use have arisen as further discussed below.

Different animal models have been used in order to analyze how sex hormones affect neurodegenerative processes. Inhibition of aromatase, the enzyme that catalyzes the nonreversible conversion of aromatizable androgens into estrogens, results in lower estrogen levels. This inhibition is associated with altered beta amyloid deposition and more severe strokes in $\mathrm{AD}$ mouse models (McCullough et al., 2003; Overk et al., 2012). Similar results have been observed with aromatase knock out (KO) mice (Yue et al., 2005). Different animal models have been used for investigating the role of sex steroids in neurodegeneration and aging, being gonadectomy one of the most used. This is a standard practice in rodent hormone replacement studies, allowing investigators more control over sex hormone levels in circulation in order to study testosterone, estradiol and/or progesterone specific actions and their interaction at different levels (Frick, 2009). Moreover, ovariectomy (OVX) in female animals, especially in rodents, is a broadly used method to model women's menopause. Like primates, rodents have reproductive cycles, which start to become irregular in middle-aged animals, i.e., 9-12 months of age in rats. However, and unlike primates, rats do not experience complete ovarian follicular loss at middle age, having chronically high circulating estradiol levels. For this reason, many laboratories often turn to the OVX rat model. Thus, using age-appropriate rats at young, middle, and old ages, surgical, peri- and natural menopause can be modeled (Morrison et al., 2006).

Several studies have shown that decreasing estrogen levels by OVX enhances neurodegenerative processes by increasing brain damage (Borrás et al., 2003; Overk et al., 2012; Yao et al., 2012; Ding et al., 2013; Kireev et al., 2014). Furthermore, restoration of estradiol levels in OVX animals by hormonal therapy reverses brain damage (Yao et al., 2012; Ding et al., 2013; Kireev et al., 2014; Lu et al., 2018). Numerous preclinical and epidemiological studies as well as some clinical trials have supported beneficial effects of HRT on memory and cognition 
and reduced risk for $\mathrm{AD}$. Yet, an initial evaluation of results from the Women's Health Initiative (WHI), the largest clinical trial involving postmenopausal women to date, suggested the contrary (Rettberg et al., 2014). However, the study population in the WHI considerably differed from women in previous observational studies regarding age or years after menopause onset at the time treatment was initiated. Later sub-analysis of data from the WHI trial as well as other epidemiological studies have provided evidence supporting the concept that there is a limited period of time around menopause during which HRT can exert positive effects on brain function. The "window of opportunity" theory suggests that beneficial effects of estrogens can only be achieved on a healthy brain; i.e., if HRT starts before or at the time of menopause. On the contrary, if HRT is initiated some years after menopause onset, it has detrimental effects on brain function and can even increase the risk of developing AD (Morrison et al., 2006; Brinton, 2008, 2009; Scott et al., 2012; Rettberg et al., 2014; Miller and Harman, 2017). Moreover, it has been suggested that effectiveness of HRT is likely to be dependent on additional factors, such as formulations of treatments regarding type (conjugated equine estrogen vs. $17 \beta$ - estradiol, medroxyprogesterone acetate vs. progesterone), mode of delivery (oral vs. transdermal) and regimen (continuous vs. cyclic) (Miller and Harman, 2017).

Apart from being a target for sex hormones, the brain is now recognized as a steroidogenic organ, and the degree to what neurosteroidogenesis, i.e., the synthesis on neuroactive steroids in the brain, affects its function has recently started to be unraveled. Neuroactive steroids are detectable in the brain after the removal of peripheral steroidogenic organs and their levels are affected by modifications in the levels of peripheral neuroactive steroids in a region-, time after gonadectomy- and sex-manner, suggesting a compensatory mechanism in the brain to counteract the effects of peripheral hormone loss (Caruso et al., 2010; Sorwell et al., 2012; Arevalo et al., 2015). Similarly to peripheral sex steroids, neurosteroids have also been described to exert neuroprotective effects. Moreover, it has been suggested that endogenously synthesized neurosteroids may reinforce the protective effects of exogenously administered steroids (Chamniansawat and Chongthammakun, 2012; Li et al., 2013). In fact, the level of brain estrogen has been shown to determine the effect of estrogen therapyinduced protection against $\mathrm{AD}$ pathology in mice (Li et al., 2013). Neurosteroids are not only synthesized de novo from cholesterol. They can also be produced through transformation of blood peripheral steroid hormones into derivatives with potent neuromodulatory actions. Consequently, although neurosteroidogenesis is regulated independently of peripheral steroidogenesis, it is expected that fluctuations in plasma steroid levels affect the rate of brain steroid synthesis (Veiga et al., 2004).

Although they have received less attention than estrogens on brain function, androgens and progesterone exert neuroprotective actions as well. Testosterone and its metabolites have been described to be neuroprotective under conditions of glucose deprivation both in hippocampal neurons (Ishihara et al., 2016) and astroglial cells (Toro-Urrego et al., 2016).
Similarly, testosterone has been shown to prevent dendritic atrophy in motoneurons after induced death of the surrounding neurons (Cai et al., 2017). Moreover, under chronic stress conditions, depletion of testosterone has been shown to increase susceptibility to oxidative damage in different brain areas (Son et al., 2016). Androgens have been suggested to have a positive impact on cognition (Colciago et al., 2015). This effect is likely to be mediated by testosterone and its metabolites in the hippocampus, where a high concentration of androgen receptors has been shown in hippocampal CA1 pyramidal cells (Colciago et al., 2015). Orchidectomy studies have described that testosterone replacement increases spine density in the hippocampus and at the same time improves spatial memory in rats (Jacome et al., 2016). Likewise, dihydrotestosterone (DHT) treatment also restores hippocampal spine density (Maclusky et al., 2006). Moreover, the proportion of immature dendritic spines increase after orchidectomy, suggesting that testosterone not only affects the number of synaptic spines, but also their maturation state (Li M. et al., 2012). The effects of testosterone on spine density and maturation are likely related to the brainderived neurotrophic factor (BDNF) expression (Gao et al., 2009; Li M. et al., 2012).

Progesterone is another major sex hormone, whose best-characterized function is reproduction regulation. Progesterone receptors are broadly expressed in the brain, and they have been described to be present in all neural cell types (Brinton et al., 2008). Together with its metabolites, progesterone exerts several physiological functions in the brain. It regulates neuronal development of Purkinje cells in cerebellum (Tsutsui et al., 2011), differentiation and proliferation of oligodendrocytes (Ghoumari et al., 2005), and synaptogenesis and neuronal plasticity (Rossetti et al., 2016) among others. On the other hand, progesterone and its metabolites have been described to exert beneficial effects in various animal models of neurodegeneration and brain damage, including PD (Bourque et al., 2009) stroke (Singh and $\mathrm{Su}, 2013$ ) traumatic brain injury and demyelination (De Nicola et al., 2009; El-Etr et al., 2015). These neuroprotective effects involve different mechanisms of action. Among them, progesterone and its metabolites activate the MAPK/ERK and PI3K/Akt pathways (Kaur et al., 2007; Baudry et al., 2013), which are well-established survival signaling pathways. In addition, progesterone also exerts neurotrophic actions regulating the expression of neurotrophins such as BDNF (Melcangi et al., 2014). Besides, progesterone modulates neuroinflammation. The anti-inflammatory effect of progesterone has been extensively investigated in an experimental multiple sclerosis murine model: autoimmune experimental encephalomyelitis (EAE). Since progesterone and its derivates promote myelin formation in the peripheral nervous system, the role that they might play in demyelinating diseases has received attention for many years. In EAE mice, progesterone itself and one of its reduced metabolites, allopregnanolone, have been shown to reduce inflammatory markers, to inhibit microglia activation and to avoid the penetration of circulating lymphocytes and macrophages in the central nervous system (CNS) (De Nicola et al., 2013, 2017; Noorbakhsh et al., 2014). This reduction in neuroinflammatory processes would mediate, at least in part, 
the beneficial effects of progesterone in EAE mice, which show reduced clinical severity, lower demyelination and improved neuronal function after progesterone treatment (Garay et al., 2007, 2009).

Remarkably, the effect of progesterone when delivered in combination with estrogen is not always positive. It is well known that progesterone regulates estrogen actions, particularly at the reproductive level (Graham and Clarke, 1997). At the CNS level, various studies have suggested that when both hormones are administered together, progesterone often antagonizes rather than synergizes estrogen effects (Bimonte-Nelson et al., 2004, 2006; Rosario et al., 2006; Carroll et al., 2008; Yao et al., 2011). Although the precise mechanism behind the antagonistic effect of progesterone on estrogen actions is poorly understood, some studies have suggested that it might be mediated, at least in part, by the regulation of ER expression (Pike et al., 2009).

\section{Sex Hormones: Mechanisms of Action in the Brain}

Similar to other steroid hormones, sex steroids exert their multiple actions through binding to nuclear receptors that act as ligand-dependent transcription factors to regulate the expression of target genes (McDevitt et al., 2008). As for estrogens, two classical receptors have been described, ER $\alpha$ and $\operatorname{ER} \beta$. However, in recent years, the existence of membrane associated ER and other proteins unrelated to ERs that also trigger estrogen responses, like membrane $G$ protein-coupled ER 1 (GPER1), has become evident (Nilsson et al., 2001; Zárate and Seilicovich, 2010; Rettberg et al., 2014). This provides an additional layer of complexity to the understanding of how sex hormones affect higher cognitive functions and other neural processes including mood, cardiovascular regulation, fine motor skills and neuroprotection (Dumitriu et al., 2010; Hara et al., 2015). Androgen and progestin receptors have also revealed both nuclear and non-nuclear forms and locations of classical and non-classical receptors (McLachlan et al., 1991; Brinton et al., 2008; Sarkey et al., 2008; Petersen et al., 2013; Li et al., 2015).

Apart from being highly expressed in regions related to reproductive behavior and neuroendocrine function like the hypothalamus, sex hormone receptors are widely distributed in the brain and are present both in nuclear and non-nuclear compartments, including mitochondria (Kelly and Levin, 2001; Boulware et al., 2007; Psarra and Sekeris, 2008; Simpkins et al., 2008; Rettberg et al., 2014; McEwen and Milner, 2017). In accordance with the complexity of the brain, sex hormones modulate not only neuronal function; they exert their actions on different cellular targets, modulating an important number of physiological processes. Thus, estrogen and progesterone have been described to regulate proliferation and maturation of oligodendrocytes (Marin-Husstege et al., 2004; Ghoumari et al., 2005) as well as local inflammation processes mediated by astrocytes and microglia (Arevalo et al., 2010). Studies in different animal models of brain injury have described that sex hormones also have an important effect in the cerebral vasculature. ERs have been localized in endothelial as well as in smooth muscle cells (Stirone et al., 2003). During stroke, estrogens exert a protective action due to theirs effect on the cerebral vasculature, increasing endothelial nitric oxide synthase activity, suppressing inflammatory markers like COX-2, and reducing leukocyte adhesion (Suzuki et al., 2009). Similarly, in a rat model of traumatic brain injury, progesterone has been described to promote angiogenic activity of endothelial progenitor cells ( $\mathrm{Yu}$ et al., 2017).

Estrogens have an important effect on mitochondrial function as well (Klinge, 2017). Although the mechanisms by which estrogen regulates mitochondrial function are not totally understood, both direct and indirect actions have been described to contribute to such regulation. Estrogen's beneficial effects in mitochondria are especially important in those tissues that have high demand of energy like the CNS. Along with metabolism regulation (Brinton, 2008; Klinge, 2017), estrogen exerts different actions involving mitochondrial function in neuronal tissues, including biogenesis (Kemper et al., 2014), apoptosis processes (Garcia-Segura et al., 1998; Nilsen and Diaz Brinton, 2003; Mo et al., 2013) and even morphology (Arnold et al., 2008; Hara et al., 2014). Many estrogen actions in mitochondria are mediated by the presence of ERs in these organelles, which seems to be cell-type specific. In relation to the brain, mitochondrial ERs have been suggested to be present in primary cultured rat neurons, murine hippocampal cell lines (Yang et al., 2004), neurons and glia of rat hippocampus (Milner et al., 2005; Herrick et al., 2006) and also in pre- and post-synaptic mitochondria of hippocampal neurons (Milner et al., 2008). The presence of ERs within mitochondria suggests that estrogen might modulate mitochondrial function by directly affecting transcription of mitochondrial DNA (mtDNA). In fact, mitochondrial ER $\beta$ has been described to bind to estrogen response element-like sequences in mtDNA (Demonacos et al., 1996; Chen et al., 2004). However, estrogen actions on mitochondria are not exclusively related to such mechanism. Estrogen also regulates mitochondrial functions through their classical nuclear mechanism, i.e., transcriptional regulation of nuclearencoded mitochondrial proteins. It is known that estrogen regulates the nuclear transcription of different proteins affecting mitochondrial function such as nuclear respiratory factor-1 (NRF-1) and peroxisome proliferator-activated receptor-gamma coactivator 1 (PCG-1) (Kemper et al., 2013; Klinge, 2017). Hence, this regulation is critical for the activation of nuclear genes encoding proteins involved in mitochondrial biogenesis as well as in the mitochondrial electron transport chain complexes (Scarpulla, 2008; Klinge, 2017). It also regulates the transcription of mitochondrial transcription factor A (TFAM), which translocates into mitochondria and initiates transcription and replication of mtDNA (Virbasius and Scarpulla, 1994; Kang et al., 2007).

Effects of estrogen in mitochondria might be especially relevant in the brain since the accumulation of mtDNA mutations and the related mitochondrial dysfunction have been suggested to play a critical role in the process of brain aging and in the onset of neurological disorders (Barja, 2004; Cantuti-Castelvetri et al., 2005; Kujoth et al., 2007). Accordingly, increased levels of oxidative modifications and mutations in 
mtDNA occur in the brain during normal aging (Melov, 2004; Beal, 2005; Vermulst et al., 2007), with enhancement of these levels in neurodegenerative diseases such as AD and PD (Gabbita et al., 1998; Sanders et al., 2014). One of the main factors contributing to mtDNA instability, both during brain aging and in neurodegenerative diseases, is the decline in mtDNA repair capacity (Imam et al., 2006; Weissman et al., 2007a; Gredilla, 2010; Gredilla et al., 2012). Different DNA repair pathways have been described both in the nucleus and mitochondria (Gredilla et al., 2010a; Jeppesen et al., 2011). The major ones are base excision repair (BER), mismatch repair (MMR), nucleotide excision repair (NER) and double-strand break repair. The main pathway taking place in mitochondria is BER, which repairs mtDNA modifications caused by alkylation, deamination and oxidation. A brief description of these repair pathways and the effect of sex-hormones on them will be described later in this review.

\section{SEX HORMONES AND BRAIN AGING}

Aging is an inevitable physiological process orchestrated by a plethora of molecular mechanisms that interact to alter body homeostasis, eventually leading to organismal functional decline and disease. While for many years the brain was not considered to be a sex-hormone-responsive organ, except the hypothalamus for reproductive function regulation, it is now well accepted that the entire brain is both a target and a source of sex hormones (Acaz-Fonseca et al., 2016; McEwen and Milner, 2017). Sex hormones exert numerous protective and antioxidant actions in the adult brain increasing neural function and resilience and promoting neuronal survival. As the organism age, a relatively rapid loss of ovarian hormones in the female after menopause, and a gradual but indeed significant decline of testosterone in men occur. Thus, it is not surprising that reproductive senescence both in males and females has a negative impact on neural function and represents a significant age-associated risk factor for neurodegenerative diseases, such as AD (Barron and Pike, 2012).

\section{Sex Hormones and Synaptic Plasticity during Aging}

The key role of estrogens and ERs in the synaptic basis of cognitive functions mediated by the hippocampus and prefrontal cortex (PFC) is well recognized (Dumitriu et al., 2010; Hara et al., 2015). Both ER $\alpha$ and ER $\beta$ are localized in synaptic terminals and dendritic spines, dendritic shafts, axons and glial cell processes in a membrane-associated manner (Milner et al., 2005; McEwen and Milner, 2007), suggesting that estrogen mediates its effects on synapses locally rather than via regulating nuclear transcription. As the brain ages, changes in the pattern of ER expression and/or in differentially activated signaling pathways in these brain areas have been suggested to be the basis for the detrimental effects of aging in memory and learning. Briefly, synapse number and spine density decrease with natural or surgical depletion of ovarian hormones in the CA1 area of the hippocampus from female rats (Gould et al., 1990; Woolley and McEwen, 1992, 1993; Adams et al., 2001). Unlike what is observed in young animals, estrogen treatment cannot restore synapse and spine density levels in aged animals, suggesting that the hippocampus becomes unresponsive to estrogen effects with age (Adams et al., 2001). Furthermore, the finding that the number of ER $\alpha$-containing synapses in the hippocampus of old female rats decreases to half the number found in young animals could explain loss of estrogen actions in the aged hippocampus, which has been suggested to be the basis for lower brain plasticity with aging (Adams et al., 2002). Unlike the hippocampus, hypothalamic levels of ER $\alpha$ and progestin receptor are maintained with age in female rhesus monkeys, while membrane GPER1 expression is increased, indicating that the aged hypothalamus retains the ability to express steroid hormone receptors at levels comparable to young adults (Naugle et al., 2014).

Despite being extensively homologous, $\mathrm{ER} \alpha$ and $\mathrm{ER} \beta$ diverge in their expression and action in the brain. They are widely expressed throughout the adult brain and their expression is differentially regulated in aging and by estrogen treatment. Like $\mathrm{ER} \alpha$, the levels of synaptic ER $\beta$ are reduced with age in the hippocampus of female rats. However, ER $\beta$ levels are increased following estrogen treatment both in young and old OVX rats, indicating that ER $\beta$-mediated effects at the synaptic level are maintained during aging in the female rat hippocampus. It suggests that ER $\beta$ would be a more sensitive target to estrogen actions in the aged female brain (Waters et al., 2011). Since ER $\beta$ signaling has been associated with altered synapse formation and plasticity (Szymczak et al., 2006; Waters et al., 2009), the shift to decreased $E R \alpha / E R \beta$ ratio has been proposed to be a major contributor to the age-induced loss of synapse formation by estrogens (Waters et al., 2011). Also, since ER $\alpha$ and ER $\beta$ are linked to unique second messenger pathways that can oppose one another, the altered $\operatorname{ER} \alpha / \operatorname{ER} \beta$ ratio can contribute to deficits in specific signaling pathways, affecting memory and plasticity in old animals (Waters et al., 2011). Moreover, clinical studies have shown a positive correlation between Mini Mental StateExam (MMSE) score and nuclear $\mathrm{ER} \alpha$ levels in the frontal cortex of $\mathrm{AD}$ patients, suggesting that decreased $\mathrm{ER} \alpha$ responsiveness is directly associated to severity of cognitive impairment (Kelly et al., 2008). On the contrary, an age-realted increase in the $\operatorname{ER} \alpha / \operatorname{ER} \beta$ ratio has been reported in cortical astrocytes from both male and female rats, which correlated with lower glial trophic support to neuronal function. The increased ratio was suggested to be associated to both long-term potentiation and spatial memory impairment (Paris et al., 2011; Arimoto et al., 2013; Yin et al., 2015).

Like females, the male brain is also responsive to variations in androgen levels at the synaptic level. The density of dendritic spines in the hippocampus has been reported to be modulated in vivo by androgen depletion and replacement (Leranth et al., 2003). Gonadectomy in male rats decreased CA1 spine synapse density compared to sham-operated animals (Jia et al., 2013). Since it can be metabolized into the androgen DHT and estradiol, testosterone can mediate its effects through androgen 
and/or estrogen pathways. Treatment of gonadectomized rats with DHT or testosterone propionate but not with estradiol restored spine synapse density to similar levels of those found in intact males, suggesting a direct role of androgens through androgen receptors rather than indirectly via local estradiol biosynthesis in hippocampal synaptic plasticity (Leranth et al., 2003). Similar results were obtained in SAMP8 mice, an animal model of accelerated aging (Jia et al., 2016; Pan et al., 2016).

\section{Sex Hormone and Growth Factor Interaction during Aging}

A functional interplay between ERs and growth factor receptors, such as insulin-like growth factor-1 (IGF-1) or BDNF, has broadly been shown to take place in the brain. Hence, it is expected that conditions that affect the expression and/or activity of these receptors have a reciprocal negative impact on the multiple processes regulated by these systems, from the control of hormonal homeostasis and reproduction to learning and cognition. For example, estrogen-induced transport of glucose in the brain through the insulin-sensitive glucose transporter GLUT-4, adult hippocampal neurogenesis and protection against stroke are processes that require the coupling between ER $\alpha$ and IGF-1 receptor, providing further evidence for the interplay between these two systems in promoting enhanced neuronal metabolism and neuroprotection (Cardona-Gómez et al., 2002; Garcia-Segura et al., 2010; Arevalo et al., 2012; Sohrabji, 2015; Huffman et al., 2017). Besides, in aged OVX animals, which had undergone estrogen replacement treatment during middle age, estrogen-induced improvement in memory function was abolished by treatment with an IGF-1 receptor inhibitor. This finding indicates that estrogen may exert part of its lasting effects on the hippocampus and memory through the IGF-1 receptor signaling pathway (Witty et al., 2013). In female rats, both reproductive senescence and OVX have been shown to consistently decrease the levels of IGF-1 gene expression, which correlates with increased expression of genes involved in $\mathrm{A} \beta$ generation (Rettberg et al., 2014). In addition, clinical studies have shown that patients with $\mathrm{AD}$ have decreased expression of insulin receptors and impaired insulin signaling in brain areas susceptible to $\mathrm{AD}$ pathology, which could account for the early cognitive impairment seen in these patients (Schiöth et al., 2012). These studies suggest that impaired brain estrogen/ER and IGF-1/IGF-1 receptor systems may account, at least in part, for the women's well known higher vulnerability to develop $\mathrm{AD}$ after menopause. Despite estrogens and androgens share metabolic pathways and functional properties, far less research has examined a functional link between IGF-1 and androgens in the brain (Huffman et al., 2017). However, some studies have shown that IGF-1/androgen interactions promote beneficial effects in neuroprotection (García-Fernández et al., 2008; Puche et al., 2008). On the other hand, BDNF is a crucial molecule for synaptic plasticity and hippocampal memory formation (Heldt et al., 2007; Bekinschtein et al., 2014). BDNF and estrogens activate a number of common signaling pathways, which converge in the induction of growth, survival, neural plasticity and learning. Estrogens can also induce BDNF gene expression through direct binding to an estrogen-sensitive response element (ERE) on the BDNF gene or by increasing neural activity that in turn upregulates BDNF (Scharfman and MacLusky, 2006). Serum BDNF levels have been reported to decline with increasing age in both men and women (Shimada et al., 2014). In addition, a significant drop in serum BDNF levels was found in women after menopause, suggesting that ovarian hormone and BDNF circulating levels are tightly associated (Bus et al., 2012). Interestingly, a recent report has shown that working memory-related hippocampal function is differentially modulated by estradiol in women carrying the specific BDNF $\mathrm{Val}^{66} \mathrm{Met}$ functional single-nucleotide polymorphism (SNP; Wei et al., 2017). A decrease in BDNF expression has been observed both during aging and after OVX in murine hippocampus (Singh et al., 1995; Sohrabji et al., 1995; Chapman et al., 2012; Perovic et al., 2013; Lu et al., 2014) and estrogen replacement treatment to OVX rats has been shown to increase BDNF mRNA or protein levels (Singh et al., 1995; Sohrabji et al., 1995; Gibbs, 1998; Kiss et al., 2012; Lu et al., 2014). Recently, it has also been suggested that estrogen-enhanced consolidation of multiple forms of hippocampal memory in middle-aged rats is associated with the induction of BDNF protein levels through non-classical cell signaling mechanisms involving epigenetic regulation of the BDNF gene (Fortress et al., 2014). Although there has been substantial growth of new data on the functional consequences of the interplay between sex hormones and these growth factors in recent years, many key aspects remain to be addressed. In particular, an area that warrants further study is to ascertain the role this interaction plays during aging and menopause, when the levels of sex hormones and IGF-1/BDNF decline and the cells and tissues that respond to them undergo both metabolic and functional changes (Garcia-Segura et al., 2010; Sohrabji, 2015).

\section{Sex Hormones and Mitochondrial Function during Aging}

Despite comprising only $2 \%$ of the body's mass, the brain consumes $20 \%$ of the body fuel to sustain its high demand of energy in the form of ATP, making it highly dependent on proper mitochondria function (Rettberg et al., 2014). As mentioned before, estrogens have beneficial effects on brain energy metabolism, increasing blood flow and glucose uptake and enhancing aerobic glycolysis coupled to the citric acid cycle, mitochondrial respiration and ATP generation (Brinton, 2008). Not surprisingly, a strong link between the drop in circulating ovarian hormones and reduced brain bioenergetics in women during menopause and in animals undergoing natural or surgical reproductive senescence has been reported (Maki and Resnick, 2000; Rasgon et al., 2005; Yao et al., 2009, 2010, 2012). In line with this, it is now recognized that normal aging and several age-related diseases, such as $\mathrm{AD}$ and $\mathrm{PD}$, are related to mitochondrial dysfunction (Chakrabarti et al., 2011; Johri and Beal, 2012). The common features observed in aging and $\mathrm{AD}$ regarding mitochondria have recently been reviewed (Grimm et al., 2016a). Briefly, the aging process is characterized by decreased mitochondrial 
activity, including impaired oxidative phosphorylation, reduced expression and activity of respiratory chain complexes and decreased antioxidant defenses (Grimm et al., 2016a). Extensive evidence indicates that the decline in brain mitochondrial function observed in reproductive senescent female animals is caused by loss of ovarian hormones (Yao et al., 2009, 2010, 2012). Also, considering that the first steps of steroidogenesis take place in mitochondria, it is reasonable to hypothesize that age-related accumulation of mitochondrial deficits may have a detrimental effect in steroid biosynthesis and comprise a potential pathogenic mechanism leading to neurodegeneration (Velarde, 2014).

OVX in young adult animals has been shown to induce adverse effects in brain mitochondrial bioenergetics similar to those found in aged animals, including reduced respiration and ATP production rates, increased oxidative stress and decreased expression and/or activity of metabolic enzymes within this organelle (Irwin et al., 2011; Shi et al., 2011; Yao et al., 2012; Gaignard et al., 2015). A recent report has shown that OVX induces mitochondrial dysfunction in terms of reduced active respiration and ATP production likely associated to alterations in the mitochondrial membrane lipid profile in the hippocampus (Zárate et al., 2017). In particular, OVX induces changes in the fatty acid profile of mitochondrial membranes rendering them more prone to peroxidation, a feature also observed during aging in an organ-dependent manner (Pamplona, 2008). Interestingly, OVX also induces a specific decrease in cardiolipin content and changes in its fatty acid composition. Importantly, cardiolipin is an essential component of mitochondria membranes that plays a crucial role in several mitochondrial processes such as oxidative phosphorylation, apoptosis, mitochondrial protein import and supercomplex formation (Claypool and Koehler, 2012). Reduced cardiolipin content, alterations in its acyl chain composition and/or increased cardiolipin peroxidation have been linked to mitochondrial dysfunction in multiple tissues during aging and in neuropathological disorders (Monteiro-Cardoso et al., 2015). Overall, these studies suggest that loss of ovarian hormones accelerates the decline in mitochondrial bioenergetics promoting a premature aging phenotype (Yao et al., 2009). In line with this, alteration in mitochondrial membrane lipid composition, especially in cardiolipin content, could be an additional player in the aging effects of ovarian hormone loss contributing to the early bioenergetic decay during menopause (Zárate et al., 2017).

Although activation of both $\mathrm{ER} \alpha$ and $\operatorname{ER} \beta$ favors mitochondrial function, ER $\beta$ activation often results in greater mitochondria functional capacity (Irwin et al., 2012; Yao et al., 2013). It has also been suggested that estrogen effects in brain metabolism mainly relies on ER $\beta$ signaling through directly promoting mtDNA gene expression, mitochondrial antioxidant defenses and oxidative and calcium buffering capacity (Nilsen and Diaz Brinton, 2003; Yang et al., 2004; Simpkins et al., 2008; Rettberg et al., 2014).

In addition to be the main source of ATP in cells, mitochondria also play important roles in other cellular functions, such as cell growth and differentiation, regulation of intracellular calcium homeostasis, apoptosis, alteration of the cellular redox state and synaptic plasticity (Grimm et al., 2016b). Mitochondria are considered the major source of ROS production in cells under physiological conditions. Electrons leak the electron transport chain during mitochondrial respiration, combining with molecular oxygen to generate $\mathrm{O}_{2}^{-\bullet}$, which subsequently can be converted to $\mathrm{H}_{2} \mathrm{O}_{2}$ by superoxide dismutase (SOD). When compared to most other tissues, the brain has very low antioxidant capacity and it is subjected to particularly high levels of oxidative DNA damage. Considerable evidence supports the role of oxidative damage in the aging process (Golden et al., 2002; Samarghandian et al., 2016) and an increasing number of studies implicate ROS as an important contributor to cognitive impairment during aging as well as in age-associated neurodegenerative diseases (Grimm et al., 2016b). Estrogens have well-known antioxidant effects. Clinical evidence points to lower brain oxidative stress and better antioxidant defenses in premenopausal women compared to men, parameters which gradually decrease as women age or if they undergo bilateral oophorectomy (Mandal et al., 2012; Bellanti et al., 2013; Rekkas et al., 2014). Similar results were obtained in animals, where brain mitochondria from young adult females showed lower peroxide production and higher levels of MnSOD, glutathione (GSH) and glutathione peroxidase (GPx) compared to males of the same age (Borrás et al., 2003). Estrogens also increase the expression of peroxirodoxin 5 and glutaredoxin in brain mitochondria (Nilsen et al., 2007). Remarkably, OVX blunted the differences in peroxide and GSH levels between females and males while estrogen treatment prevented them, highlighting the protective effects of this steroid against oxidative stress (Borrás et al., 2003). A similar pattern of a positive correlation between circulating testosterone levels and the activity of antioxidant enzymes both in serum and in the hippocampus have been reported in men and in orchidectomized rats, respectively (Meydan et al., 2010; Cunningham et al., 2014). Again, these effects were prevented in animals after testosterone administration (Meydan et al., 2010).

Some brain areas seem to have a particularly high vulnerability to the effects of sex hormone deprivation, aging and oxidative stress. Thus, several studies have reported a link between hippocampal synaptic decline, cognitive impairment and increased risk of neurodegeneration after OVX in animal models and menopause in women (Morrison et al., 2006; Brinton, 2009; Velarde, 2014; Hara et al., 2015). Mitochondrial dysfunction and oxidative damage are also more evident in the hippocampus than in brain cortex or whole brain in aged male rodents (Navarro et al., 2008). Moreover, OVX severely induces a decrease in the activity of SOD together with an increase in the pro-oxidant enzyme monoamine oxidase (MAO) in the hippocampus but not in the cortex of young rats (Huang and Zhang, 2010). Overall, increasing evidence indicates that the hippocampus is an early target of aging, sex hormone loss and oxidative stress (Navarro et al., 2008; Paradies et al., 2011; Hara et al., 2015).

Another brain region highly sensitive to ovarian hormones is the PFC, an area tightly associated to cognitive function in humans. A recent report has shown that aging in non human 
primates induces morphological changes in mitochondria from this brain area leading to a mitochondrial phenotype related to enhanced oxidative stress and ROS production. Noteworthy, this correlates with worsening of working memory. Interestingly, OVX promoted similar effects in mitochondrial morphology and cognitive behavior, which was reversed by estradiol treatment. These studies suggest that estrogen effects on PFC-related memory can result from its antioxidant capacity leading to improved mitochondrial health (Hara et al., 2014).

\section{Sex Hormones and Neurosteroidogenesis during Aging}

Another process that has been described to be affected by aging is the synthesis of neurosteroids. The transport of cholesterol from the outer to the inner mitochondrial membrane is the first and rate-limiting step in steroidogenesis. For many years, there has been general agreement that this trafficking relies on the activity of at least two proteins, steroidogenic acute regulatory protein (StAR) and translocator protein of $18 \mathrm{kDa}$ (TSPO), previously known as peripheral benzodiazepine receptor (PBR; Veiga et al., 2004; Acaz-Fonseca et al., 2016). However, recent research using genetic depletion of TSPO both in in vivo and in vitro models has challenged the view of TSPO as a critical enzyme for steroidogenesis (Selvaraj et al., 2015). A recent report suggested that TSPO may be functionally redundant in achieving baseline steroidogenesis although it may play an important role in maintaining androgen levels during aging (Barron et al., 2017). It is important to stress that the expression and activity of both enzymes are increased with aging and after brain injury, suggesting that the production of brain steroids can be modulated as a protective mechanism to cope with decreased peripheral steroids or pathological conditions (Veiga et al., 2004).

Also, other enzymes catalyzing different steps in neurosteroidogenesis are differentially expressed in neurons and glia in a region and pathophysiological-condition manner. Under physiological conditions, neurons are the main sites for brain estrogen production, relying on their high expression of aromatase (Acaz-Fonseca et al., 2016). However, enhanced aromatase expression in astrocyes has been reported following brain injury in rats and also in the human PFC in the late stages of $\mathrm{AD}$, suggesting that neuronal impairment can induce estrogen production as a glial protective mechanism against neuronal death (Veiga et al., 2004; Luchetti et al., 2011; Acaz-Fonseca et al., 2016). A recent report has shown decreased levels of aromatase in the hippocampus of aged female mice when compared to the levels detected in adult mice (Zhao et al., 2017). OVX also downregulates aromatase gene expression in the hippocampus of middle-aged rats (Sárvári et al., 2014). Female brain-derived estradiol levels have been reported to mirror estradiol circulating levels and thus significantly decline in postmenopausal compared to premenopausal women (Rosario et al., 2011). Since the level of the estradiol precursor and aromatase substrate testosterone is also decreased in the female cerebral cortex after OVX (Caruso et al., 2010), it is tempting to speculate that brain-derived estradiol levels would also be decreased in the brain after surgical loss of ovarian hormones.
It has been reported that the inhibition or null mutation of brain aromatase results in accelerated neurodegeneration (Azcoitia et al., 2003). Furthermore, genetic variants in human aromatase have been reported to confer an increased risk for AD (Iivonen et al., 2004; Huang and Poduslo, 2006). Depletion of aromatase in an animal model of $\mathrm{AD}$ also led to earlier and more severe neuropathology than what was observed in OVX control mice, suggesting that depletion of brain-derived estrogen rather that peripheral blood estrogen is a more direct and significant risk factor for developing $\mathrm{AD}$ and points to the importance of preserving neurosteroidogenesis for healthy brain aging (Cui et al., 2013). Indeed, targeting key enzymes involved in brain estrogen production have been proposed as pharmacological targets to ameliorate brain function decline during aging and to prevent neurodegenerative diseases (Veiga et al., 2004).

\section{Sex Hormones and Neuroinflammation during Aging}

As reviewed so far, a wide variety of profound physiological changes occur during aging in the brain. The immune system is not an exception, shifting from a resting, surveying state to a chronic mild inflammatory one (Nissen, 2017). Neuroinflammation is choreographed by microglia and astroglia, both of which are affected with aging. Microglia constitute the resident immunocompetent cells of the CNS. It modulates the inflammatory response under pathological conditions but it also maintains homeostasis in the healthy brain through immune surveillance of the brain parenchyma. Changes in microglial cells during aging and in neurodegenerative processes as well as sex-related differences have recently been reviewed (von Bernhardi et al., 2015; Nissen, 2017). Aging promotes the dysregulation of microglia. As a result, an impairment of their physiological neuroprotective functions occurs. At the same time, a mild chronic inflammatory environment characterized by an increased production of inflammatory cytokines and ROS takes place in the CNS. Aged microglia displays morphological changes and a less dynamic response to injury; however, they appear to be activated under mild stimulatory events or minor injuries, responding in an exacerbated way to local and peripheral signals (Nissen, 2017).

Sex differences in gene expression across age in adult human brain have been reported. Thus, women display higher age-related increases in expression of genes associated with immune and inflammatory functions than men (Christensen and Pike, 2015). While both men and women show increased expression of these genes in the hippocampus and entorhinal cortex, only women have significant increases in other brain regions, suggesting a more global pro-inflammatory state in the aged female brain (Berchtold et al., 2008). Also, postmenopausal women display higher expression of macrophage-associated genes in the aging frontal cortex than premenopausal women, suggesting that ovarian hormone loss shifts the microglia phenotype from the resting towards the reactive state (Sárvári et al., 2012). 
It is well known that activated microglia can be polarized into a proinflammatory/cytotoxic M1 or an antiinflammatory/neuroprotective M2 phenotype in response to a myriad of physiological and pathological stimuli (Villa et al., 2016; Labandeira-Garcia et al., 2017). It has been broadly reported that estrogens trigger the polarization of microglia to an M2 phenotype (Habib and Beyer, 2015). This estrogen action becomes especially relevant under chronic inflammation conditions, where perpetuation of microglial proinflammatory status induce neuronal damage. Hence, it could provide an explanation for the neuroprotective effects of estrogens observed in aging and neurodegenerative diseases (Gyenes et al., 2010; Selvamani et al., 2012; Siani et al., 2017). Besides, growing evidence has highlighted the role of the local renin-angiotensin system in aging and several processes mediated by microglial activation and neuroinflammation (Hellner et al., 2005; Kerr et al., 2005; Rey et al., 2007; Rodriguez-Pallares et al., 2008; Torika et al., 2016). Interestingly, estrogen-induced inhibition of this system leads to reduced oxidative stress, neuroinflammation, and neurodegeneration of dopaminergic neurons in murine models of $\mathrm{PD}$, which may explain, at least in part, the lower risk of developing the disease in premenopausal vs. postmenopausal women and men (Rodriguez-Perez et al., 2010; Labandeira-Garcia et al., 2016).

Like humans, female rodents display enhanced inflammation in the brain with aging, which is regulated, at least in part, by estrogen status. When compared to age-matched males, female mice show higher induction of inflammation-related genes, especially of microglia-specific ones, in the hippocampus (Mangold et al., 2017). In addition, gene expression studies in the rat frontal cortex and hippocampus have shown that both aging and ovarian hormone loss increase the expression of several microglial and immune function genes, leading to a shift towards a more inflammatory and reactive microglia phenotype (Sárvári et al., 2011, 2012, 2014). Estrogen replacement treatment attenuates the OVX-induced effects and most of these effects are mimicked by both $\mathrm{ER} \alpha$ and $\mathrm{ER} \beta$ agonists, suggesting that both ERs are targets of estrogens in microglia (Sárvári et al., 2011, 2014). Besides, both aging and OVX increase the gene expression of pro-inflammatory cytokines such as TNF $\alpha$ and IL-1 $\beta$ in the hippocampus of aged mice (Benedusi et al., 2012). It has been shown that aging exacerbates microglial response to OVX, indicating that loss of sex hormones increase the susceptibility of aged microglia to inflammation (Lei et al., 2003). Recently, it has been suggested that a form of estrogen resistance may be involved in the impaired ability of microglia to resolve inflammation during aging (Villa et al., 2016). Astroglial cells also display a proinflammatory phenotype during aging, expressing and secreting increased levels of inflammatory markers such as TNF- $\alpha$, IL- $1 \beta$ and IL-6 and hence contributing to brain neuroinflammation. They also display age-related increased levels of intermediate glial fibrillary acidic protein (GFAP) and vimentin filaments as well as increased accumulation of proteotoxic aggregates (Salminen et al., 2011). Taken together, both preclinical and clinical data indicate that both aging and menopause lead to increased neuroinflammation, which may contribute to sex differences in age-related neurological diseases such as stroke and $\mathrm{AD}$.

Although the age-induced increase in the expression of GFAP has been the most classical change reported in astroglial cells (Schipper, 1996; Unger, 1998; Cotrina and Nedergaard, 2002; Lynch et al., 2010), experimental data suggest that physiological brain aging and early stages of neurodegenerative disease are characterized by an increased number of dystrophic astrocytes (Oddo et al., 2003; Broe et al., 2004; Mena and García de Yébenes, 2008; Rossi et al., 2008; Bradford et al., 2010; Olabarria et al., 2011; Cerbai et al., 2012; Kulijewicz-Nawrot et al., 2012; Beauquis et al., 2013). These cells are smaller and less complex, with reduced capacity for glutamate uptake and decreased activity of glutamine synthetase, hence displaying reduced neuroprotective and homeostatic potential (Verkhratsky et al., 2014).

Taken together, aging promotes profound changes in morphological and functional parameters within the brain, most of which are recapitulated by sex hormone loss, particularly in the female (Figure 1).

\section{DNA REPAIR AND BRAIN AGING}

The DNA in brain cells is frequently damaged and if this damage is not removed it can have serious consequences such as compromised genomic stability. Although exogenous sources of DNA damage exist and replication errors may lead to DNA strand breaks, the majority of DNA lesions in non-replicating brain cells are introduced endogenously by ROS. It is important to note, though, that there are other common DNA lesions that have recently been recognized to also substantially impact genome stability. Among these, rNTP incorporation into DNA, genome damage from transcription-associated R-loop formation (hybridization of nascent primary RNA transcripts to the transcribed DNA strand), and aberrant topoisomerase activity are potential threats to the neural genome (McKinnon, 2016; Williams et al., 2016). Also, the generation of DNA damage through topoisomerase I cleavage complexes formed during transcription is likely to play a significant role in neurons due to the high transcription rates in these cells (Katyal et al., 2014). The difference in replicative status influences to some extent the damage and repair processes in cells. In this context it is important to note that the brain is composed of both non-dividing and dividing cells. As mentioned above, neurons are in a post-mitotic state. But glial cells (e.g., astrocytes, oligodendrocytes and microglia) are in either a proliferative or non-proliferative state, depending on their differentiation status. Because both neurons and glial cells are required to carry out the various higher-order brain functions, it is critically important to maintain all cell types in an appropriate number and configuration (Iyama and Wilson, 2013).

When DNA is exposed to ROS, it may result in oxidative base modifications. Among these, 8 -oxo-dG is one of the most abundant and well characterized (Dizdaroglu et al., 2002). It has been estimated that approximately 180 guanines are oxidized to 8-oxo-dG per mammalian genome per day (Lindahl, 


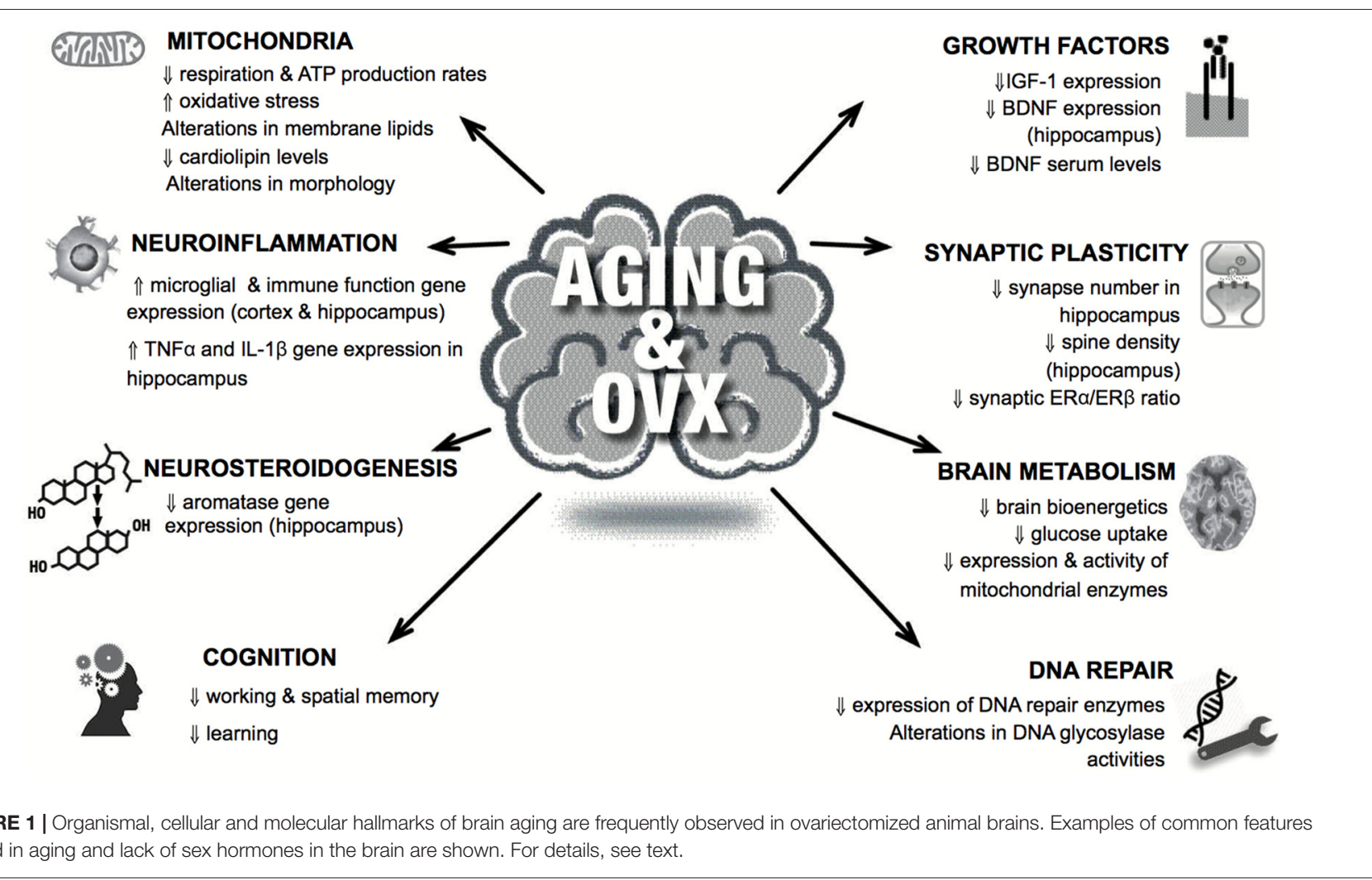

1993). These lesions may cause G:C to T:A transversion mutations because 8 -oxo-dG can base pair with adenine as well as cytosine during DNA replication (Shibutani et al., 1991). 8-oxodG has also been implicated in an event called transcriptional mutagenesis (TM), whereby a mis-incorporated adenine in the transcribing mRNA leads to the generation of mutated species of protein (Bregeon et al., 2009). Interestingly, it has recently been suggested that TM may contribute to $\alpha$-synuclein aggregation and the pathogenesis of PD (Basu et al., 2015). It is important to note that e.g., 8-oxo-dG may also become further oxidized into secondary oxidation products such as guanidinohydantoin $2^{\prime}$-deoxynucleoside (dGh) in doublestranded DNA or spiroiminodihydantoin 2 '-deoxynucleoside (dSp) in single stranded DNA (Suzuki et al., 2001; Fleming and Burrows, 2013). ROS may also give rise to DNA single strand breaks (SSBs), which are some of the most common DNA lesions arising at an estimated rate of tens of thousands per cell per day (Lindahl, 1993). Persistent SSBs can lead to the collapse of the replication fork during chromosome duplication, but they may also block transcription. Double strand breaks (DSBs) may also be formed as a result of the actions of ROS. Although these lesions normally are relatively rare, DSBs are some of the most deleterious forms of DNA damage, causing translocations and loss of genomic information. Finally, ROS can also lead to lipid peroxidation, whose byproducts can also react with DNA to produce exocyclic DNA lesions (Yu et al., 2016).

There is growing evidence for the accumulation of unrepaired DNA lesions in the CNS during both normal and accelerated aging and progressive neurodegeneration, but the observed changes depend on brain region, cell types and sub-cellular location of the DNA. Rutten et al. (2007) reported that the number of SSBs increases substantially with aging in the nuclear DNA (nDNA) of hippocampal pyramidal and granule cells as well as in cerebellar granule cells but not in cerebellar Purkinje cells in the mouse brain. For rat brain it has been reported that Ogg1-sensitive sites (i.e., mainly 8-oxo-d-G) accumulate continuously through adulthood and old age in both neurons and astrocytes (Swain and Subba Rao, 2011). Furthermore, it has been shown that susceptibility to oxidative DNA damage is lower and BER capacity is higher in undifferentiated human SH-SY5Y neuro-blastoma cells than in neuronally differentiated SH-SY5Y cells (Sykora et al., 2013). Due to the close proximity of the mtDNA to the site where most of the cellular ROS is formed, mtDNA is particularly vulnerable to oxidative damage. Accordingly, age-associated accumulation of DNA damage is mostly reported for mtDNA. It has been reported that human brain cells experience a progressive increase in the levels of 8-oxo-dG and the magnitude of the age-related damage is approximately ten-fold greater in mtDNA than in nDNA (Wang et al., 2005, 2006; Lovell and Markesbery, 2007).

If left unrepaired, DNA damage can give rise to genomic instability and trigger signaling cascades leading to cellular senescence or cell death, which are phenotypes associated with aging (Rodier et al., 2009). Accordingly, increased levels of mutations in the DNA have been described to occur in the brain and other tissues during normal aging leading to DNA 


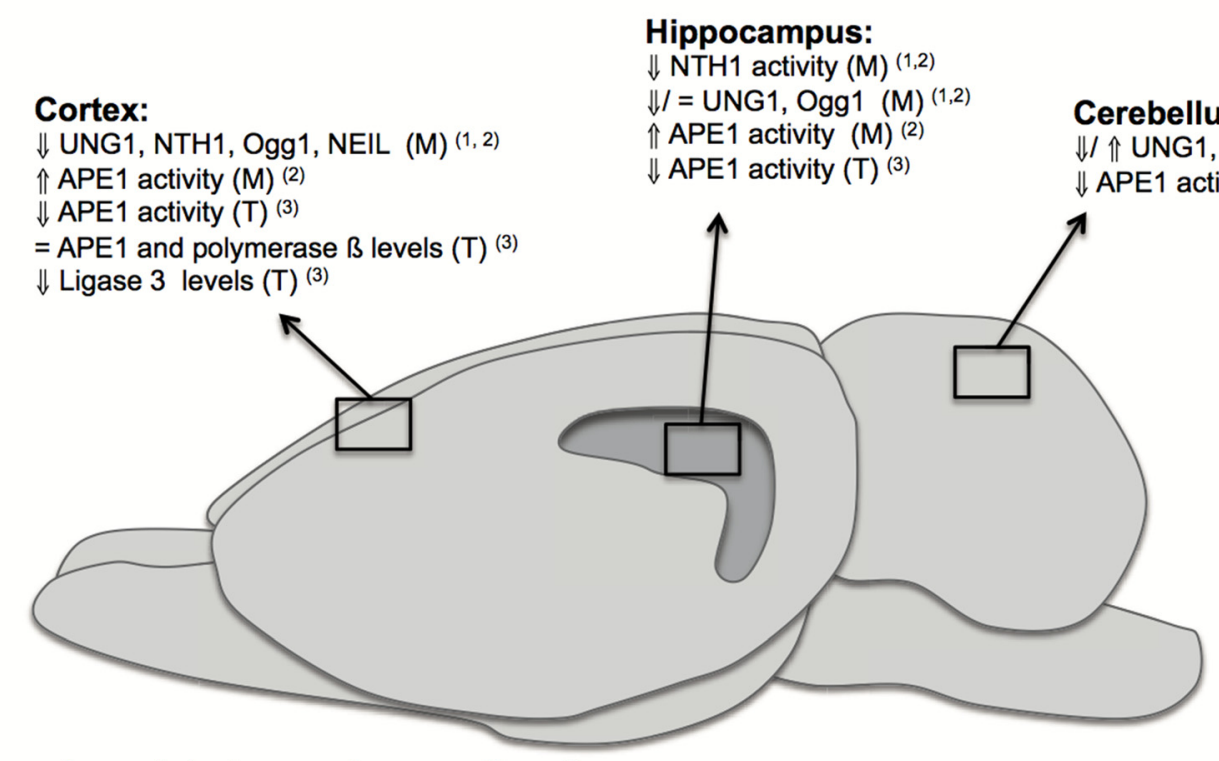

Age-related neurodegenerative diseases

$\mathrm{AD}$

[ Lower DNA glycosylase activities (Ogg1, UNG1)

Lower GAP- filling activity

Lower Total BER actvity

Lower mitochondrial and total NEIL1 levels

Lower mitochondrial and total $5 \mathrm{OHU}$ incision activity

Lower OGG1 activity and levels (9-10)

Polymorphisms and mutations of polymerase $\gamma$ are associated with PD (11)

OGG1 is involved in CAG expansion in HD (12)
Whole brain:

$\Downarrow$ UNG1, Ogg1 activity (M) (3)

$\Downarrow$ APE1 activity (M) (3)

$=$ Polymerase $\gamma$ activity (M) (3)

$=$ DNA ligase activity $(\mathrm{M})^{(3)}$

$\Downarrow$ Total BER (M) ${ }^{(3)}$

$\Downarrow$ UNG1, APE1 levels (S) (4)

$\Downarrow$ UNG1, APE1 activity (S) (4)

$\Downarrow$ Total BER (S) (4)

$\Downarrow$ Polymerase $B$ activity $(\mathrm{N}){ }^{(5)}$

$\Downarrow$ Total BER (N) ${ }^{(5)}$

FIGURE 2 | Changes in base excision repair (BER) in brain aging and neurodegeneration. The figure depicts age-related changes in the BER pathway from different investigations performed in specific brain regions: cortex, hippocampus, cerebellum; or using whole brains and in different fractions: (M): mitochondrial, (N): nuclear, (S): synaptosomal, (T): total. It also summarizes some of the major findings in humans and rodents implicating BER in age-related neurodegenerative diseases. Numbers in brackets correspond to references: (1) Imam et al. (2006); (2) Gredilla et al. (2010b); (3) Kisby et al. (2010); (4) Gredilla et al. (2012); (5) Cabelof et al. (2003); (6) Weissman et al. (2007b); (7) Canugovi et al. (2014); (8) Lovell et al. (2000); (9) lida et al. (2002); (10) Shao et al. (2008); (11) Coppedè and Migliore (2015); (12) Kovtun et al. (2007).

instability (Gredilla, 2010). Although the majority of known DNA repair pathways are present in neurons and glia cells, many investigations suggest that BER impairment and increased DNA instability are the principal contributors to brain aging and age- associated neurodegenerative diseases (Figure 2). The BER pathway is basically divided in four distinct steps. First, DNA glycosylases recognize and remove the modified bases. These DNA glycosylases, such as NTH1 and Ogg1, have distinct substrate specificities. They render an abasic site, which is mainly processed by the AP endonuclease (APE1). BER may proceed through two different sub-pathways, both in nuclei and mitochondria: short- or long-patch BER. Both pathways mainly differ in the number of nucleotides that are incorporated into the gap by a DNA polymerase. Different accessory proteins are involved in this step. Finally ligation of the DNA strand takes place by a DNA ligase (Robertson et al., 2009; Liu and Demple, 2010).
Together with BER, it has been suggested that proteins involved in MMR and DSBs repair are present in mitochondria; however, no evidence of mitochondrial NER activity has been reported (Gredilla et al., 2010a). The NER pathway repairs different types of helix distorting and bulky lesions. Moreover, this pathway plays a critical role in DNA crosslinks repair. Similarly to other DNA repair pathways, NER involves various steps, including damage recognition, opening of the DNA helix, incision of the nucleotides surrounding the lesion, gap filling and ligation. Two NER sub-pathways exist: the global genome (GG)-NER and transcription coupled (TC)-NER. The first step of the pathway, recognition of the damage, involves the action of multiple proteins. In GG-NER destabilization of the base pairing is detected by XPC together with the human homolog $\operatorname{Rad} 23$ protein, which is suggested by many studies to be the first protein factor to arrive at the lesion. For specific types of lesions, such as UV-induced photoproducts, other proteins are 
involved i.e., UV-damaged DNA-binding protein (UV-DDB), thereby recruiting XPC and extending the substrate specificity (Sugasawa, 2011). In TC-NER, damage recognition is caused by the blockage of the transcribing RNA polymerase II on the damaged DNA template. TC-NER is initiated by the CSB protein, followed by CSA. In both GG-NER and TC-NER, the lesion recognition step is followed by recruitment of TFIIH. DNA is unwound around the lesion and the open complex is stabilized by XPG and XPA. Specific endonucleases XPG and ERCC1/XPF cleave the lesion, and after removal of a 24-32 nucleotide fragment, the remaining single-strand gap is filled by the replication machinery and the resulting nick is sealed by ligase I or ligase III (de Boer and Hoeijmakers, 2000; Jeppesen et al., 2011). In MMR, MSH2-MSH6 or MSH2-MSH3 heterodimeric ATPase complexes recognize and bind the mismatch. After recruitment of different proteins e.g., MLH1, PMS2, PCNA, excision is performed by the exonuclease EXO1. Repair synthesis is accurately performed by Pol $\delta$, and ligation of the remaining nicks after DNA synthesis is performed by ligase I (Jiricny, 2006). The DSB repair pathway is regulated by several phosphorylation events, starting immediately after DSB formation, where large numbers of the histone protein $\mathrm{H} 2 \mathrm{AX}$ are phosphorylated $(\gamma \mathrm{H} 2 \mathrm{AX})$ and accumulate in the chromatin around the break (Bonner et al., 2008; Muslimovic et al., 2008). Moreover, different DSB damage response proteins accumulate in foci around DSBs, activating signaling pathways that affect events related to DNA repair, cell cycle checkpoints, and transcription. The repair of DSBs involves one of two mechanisms: non-homologous end-joining (NHEJ), directly joining the broken ends and involving loss of genetic material, or homologous recombination (HR), which can only take place in replicating cells and uses the intact sister chromatid as a template for repair.

Several studies have shown that oxidative DNA damage do accumulate with age, especially in the mitochondria. The DNA glycosylase Ogg1, is likely to be particularly important for DNA maintenance in the brain due to its specificity for the common 8-oxo-dG lesion. Ogg 1 activity decreases significantly with age in neuronal extracts of rat brain, and a similar trend is observed, to a lesser extent though, in rat brain astrocytes (Swain and Subba Rao, 2011). The glycosylases NEIL1 and NEIL2, are also considered to be essential for neuronal DNA repair, due to their ability to remove various oxidatively damaged bases in single stranded regions of DNA, since neuronal DNA is heavily transcribed and during that process the DNA is transiently in a single stranded conformation. In aged rats the activity of APE1, the major enzyme responsible for incision of the DNA backbone in BER, is reduced in the frontal/parietal cortex, cerebellum, brainstem, midbrain and hypothalamus compared to young rats (Kisby et al., 2010) and APE1 activity seems to be reduced both in neurons and astrocytes (Swain and Subba Rao, 2011). While APE1 activity declines with age, there does not seem to be any change in the protein levels of either APE1, Pol $\beta$ or LIG3 in the rat frontal/parietal cortex, suggesting that the reduced APE activity could be due to altered post-translational modification.

Mitochondrial DNA repair is likely to be particularly important due to the heavy exposure of mtDNA to ROS. Studies by Hollensworth et al. (2000) indicate that mtBER is more efficient in astrocytes than oligodendrocytes or microglia, and that the efficient repair associates with reduced susceptibility to apoptosis. We have previously reported age-associated changes in mtBER activity in the murine brain and showed that these changes are region specific. Thus, in cortical mitochondria, DNA glycosylase activities peak at middle-age followed by a significant drop at old age. However, only minor changes are observed in hippocampal mitochondria during the whole lifespan. Furthermore, DNA glycosylase activities are lower in hippocampal than in cortical mitochondria (Gredilla et al., 2010b). Noteworthy, we have also reported that an age-related decline in mouse brain mtBER occurs specifically at the synapses, which is associated with a decrease in the level of BER proteins (Gredilla et al., 2012). In the human brain, the expression of at least some genes coding for proteins involved in BER has been shown to fluctuate with aging. Interestingly, this seems to some extent to be due to an age-associated accumulation of oxidative lesions in the promotor regions of these genes (Lu et al., 2004). Recently, work from Lillenes et al. (2011, 2017), suggests a potential link between specific SNPs in APE1 and DNA polymerase $\beta$ in humans and reduced cognitive performance in healthy elderly individuals, which is in support of a role for BER in the maintenance of brain function late in life.

\section{SEX HORMONES AND DNA REPAIR IN THE BRAIN}

As mentioned above, DNA instability is one of the major hallmarks of aging. Several investigations have associated brain aging and age-related neurodegenerative disorders with higher accumulation of DNA mutations due, at least in part, to a reduction in DNA repair capacity (Vermulst et al., 2007; Jeppesen et al., 2011; Sanders et al., 2014). Since sex steroids have been described to exert neuroprotective effects, it is likely that such effects might be partly linked to a direct impact on DNA repair mechanisms. In fact, the effect of sex steroids on DNA damage responses have been extensively investigated in cancer, where sex steroids have been described to interact with different DNA repair pathways (Caldon, 2014). Estrogen and androgens positively regulate the repair of DSBs by activation of NHEJ in breast and prostate cancers (Schiewer and Knudsen, 2016). However, conflicting results have been reported regarding the effect of sex steroids on HR depending on the type of cancer, with positive regulation in prostatic cancer and melanoma (Fang et al., 2013; Bowen et al., 2015), but negative in medulloblastoma (Urbanska et al., 2009). Estrogen has also been associated with an enhanced DNA repair via MMR in colorectal cancer (Lu J. Y. et al., 2017). Regarding NER, estrogen up-regulates the repair of UV-induced DNA damage in breast cancer cells (Boulay and Perdiz, 2005) while reducing the repair of thymine dimers in human keratinocytes (Evans et al., 2003). Moreover, in patients with basal cell carcinoma, postmenopausal women show a significant drop in lymphocyte DNA repair capacity compared to postmenopausal women on estrogen supplementation (Grossman and Wei, 1995). 
Poly (ADP-ribose) polymerases (PARP) are members of a family of enzymes that are particularly abundant in cell nuclei and can function as sensors of DNA damage. Various investigations have reported sex differences in PARP1 activity. A recent report has shown that female and estrogen-treated male mice are completely protected from alkylation-induced nephrotoxicity in a transgenic model of enhanced alkyladenine DNA glycosylase (Aag) expression together with PARP-1 KO (AagTg/Parp1-/-). This sex dimorphism suggests a direct interaction between Aag and/or PARP1 with estrogen pathways leading to changes in DNA repair activity and/or gene expression (Calvo et al., 2016). Estrogen supplementation also affects PARP-1 activity differently in peripheral blood mononuclear cells from male and female mice (Zaremba et al., 2011). Moreover, PARP-1 is an important regulator of neuronal cell death and cellular responses to DNA damage and it has been reported that PARP-1 mediated cell death is dependent on androgen-receptor signaling after stroke (Vagnerova et al., 2010).

In contrast to cancer research, the relation of sex steroid hormones and DNA repair pathways and whether the former regulates the latter contributing to their neuroprotective effect has not been extensively investigated. However, various studies have reported that sex steroids, particularly estrogen and progesterone, regulate DNA repair mechanisms in the brain. Most of those studies have used OVX animals as a model for analyzing their effect on specific activities or expression of DNA repair enzymes. Studies on how estrogen levels affect DNA repair in the brain have mainly focused on enzymes involved in BER. Estrogen has been described to regulate the transcription as well as the translocation within different cellular compartments of BER enzymes. Neuroprotection of estrogens has been shown in cerebral cortex where they have been described to reduce oxidative DNA damage after hypoxia (Rao et al., 2011), an effect that is associated with an enhancement in the transcription of DNA repair enzymes like APE1 in that brain region (Dietrich et al., 2013). Moreover, estrogen supplementation in OVX old female macaques has been shown to increase the transcription levels of different DNA repair enzymes in the dorsal raphe (Bethea et al., 2016). Bethea et al. (2016) described a significant increase in the transcription of DNA repair enzymes involved in different pathways, including BER (APE1, NTH1 among others), NER (RAD23 and GTF2H5, a subunit of THIIF) and HR (NBS1 and SHFM1). Interestingly, they also reported that when estrogen is combined with progesterone the effect is reduced or even absent (Bethea et al., 2016). That is in agreement with those studies that have previously reported an antagonistic effect of progesterone over estrogen, e.g., in cognitive function of hormone-treated OVX rats (Bimonte-Nelson et al., 2006) and in hippocampal cellular survival after treatment with kainate or mitochondrial toxins (Rosario et al., 2006; Carroll et al., 2008; Yao et al., 2011). Similarly, progesterone has also been described to reduce the estrogen-related enhancement of BDNF in OVX rats (Bimonte-Nelson et al., 2004). This is especially interesting, because BDNF has been described to enhance neuronal survival, at least in part by inducing the transcription of DNA repair enzymes such as APE1 (Yang et al., 2014). Thus, the effect of estrogen on DNA repair might also be related to BDNF levels, since as we previously described, estrogens induce BDNF expression. Various studies have also linked beneficial effects of estrogens with an up-regulation of Nrf-2 via the PI3K/Akt signaling pathway. This is a relevant link since Nrf2 has been associated to the transcription of antioxidant response elements, including different DNA repair enzymes (Jayakumar et al., 2015; Habib et al., 2016). The expression of Nrf2 has been described to be reduced after OVX and restored to normal levels after estrogen supplementation in murine hippocampus (Li et al., 2017). This mechanism has also been described to play an important role in the protective role of estrogens after light-induced degeneration in retina (Zhu et al., 2015). Moreover, it has been described that certain phytestrogens exert their beneficial effects by activating the PI3K/Akt/Nrf2 pathway through ER binding (Hwang and Jeong, 2010).

Estrogen not only regulates the expression/activity of DNA repair enzymes, it has also been described to regulate their subcellular distribution. Leclère et al. (2013) have shown that in whole brain extracts, APE1 activity is increased in mitochondrial fractions after OVX. The same effect is observed in liver extracts, being associated with a translocation of APE1 from the cytosol to the mitochondria. Moreover, this effect of estrogen on the trafficking of DNA repair enzymes has been suggested to be brain region-dependent. Araneda et al. (2005) have shown that after estrogen supplementation in OVX rats, Ogg1 was translocated within the nucleus and to other cellular compartments in the paraventricular nucleus of the hypothalamus but not in the bed nucleus of the stria terminalis. This translocation of DNA repair enzymes dependency on estrogen levels might be associated with the increased oxidative stress that has been described to occur after OVX (Borrás et al., 2003; Baeza et al., 2008). Various studies have reported that DNA repair enzymes can be specifically translocated to nuclei and mitochondria in response to increased oxidative stress and DNA damage (Mitra et al., 2007; Boesch et al., 2011; Li M. X. et al., 2012).

\section{CONCLUDING REMARKS}

Brain aging is associated with an important decline in neuronal function. The drop in sex hormone levels during aging is believed to play an important role in the loss of neuronal function, which may further contribute to the onset of age-related neurodegenerative diseases. A broadly used animal model for investigating the effects of sex hormones in brain aging and neurodegeneration is gonadectomy, especially in rodents. Gonadectomized young rodents display several features of intact aged animals, including changes in brain metabolism, mitochondrial function, and neuroinflammation among others. Interestingly, estrogen supplementation in female rodents has been described to revert the negative effects of OVX in brain functionality. Different studies have supported the neuroprotective effect of estrogen at different levels. Such effect may be extremely complex, and it may depend not only on the type of receptor involved, but also on the timing of estrogen therapy. In view of ER $\beta$ sustained actions on plasticity during aging in the female brain and its effects 
on mitochondrial function, ER $\beta$ appears as a target worth exploring to counteract age-associated detrimental effects in the brain. A better understanding of the underlying mechanisms of sex hormone actions may lead to new avenues for treatment of age-associated neurodegeneration. Recently, some studies have reported a significant effect of estrogens on DNA repair enzymes in the brain. However, the investigations on this particular issue and the related mechanisms are still scarce. Since reduction in DNA repair capacity has been suggested to contribute to brain aging and the onset of neurodegenerative diseases, it is critical to fully understand how estrogens affect DNA repair mechanisms. This novel interplay warrants further study in an attempt to find new therapeutic targets to promote healthy brain aging and prevent age-related diseases.

\section{REFERENCES}

Acaz-Fonseca, E., Avila-Rodriguez, M., Garcia-Segura, L. M., and Barreto, G. E. (2016). Regulation of astroglia by gonadal steroid hormones under physiological and pathological conditions. Prog. Neurobiol. 144, 5-26. doi: 10.1016/j.pneurobio.2016.06.002

Adams, M. M., Fink, S. E., Shah, R. A., Janssen, W. G., Hayashi, S., Milner, T. A., et al. (2002). Estrogen and aging affect the subcellular distribution of estrogen receptor- $\alpha$ in the hippocampus of female rats. J. Neurosci. 22, 3608-3614.

Adams, M. M., Shah, R. A., Janssen, W. G., and Morrison, J. H. (2001). Different modes of hippocampal plasticity in response to estrogen in young and aged female rats. Proc. Natl. Acad. Sci. U S A 98, 8071-8076. doi: 10.1073/pnas. 141215898

Araneda, S., Pelloux, S., Radicella, J. P., Angulo, J., Kitahama, K., Gysling, K., et al. (2005). 8-oxoguanine DNA glycosylase, but not Kin17 protein, is translocated and differentially regulated by estrogens in rat brain cells. Neuroscience 136, 135-146. doi: 10.1016/j.neuroscience.2005.06.080

Arevalo, M. A., Azcoitia, I., and Garcia-Segura, L. M. (2015). The neuroprotective actions of oestradiol and oestrogen receptors. Nat. Rev. Neurosci. 16, 17-29. doi: $10.1038 / \mathrm{nrn} 3856$

Arevalo, M. A., Ruiz-Palmero, I., Scerbo, M. J., Acaz-Fonseca, E., Cambiasso, M. J., and Garcia-Segura, L. M. (2012). Molecular mechanisms involved in the regulation of neuritogenesis by estradiol: recent advances. J. Steroid Biochem. Mol. Biol. 131, 52-56. doi: 10.1016/j.jsbmb.2011.09.004

Arevalo, M. A., Santos-Galindo, M., Bellini, M. J., Azcoitia, I., and GarciaSegura, L. M. (2010). Actions of estrogens on glial cells: implications for neuroprotection. Biochim. Biophys. Acta 1800, 1106-1112. doi: 10.1016/j. bbagen.2009.10.002

Arimoto, J. M., Wong, A., Rozovsky, I., Lin, S. W., Morgan, T. E., and Finch, C. E. (2013). Age increase of estrogen receptor- $\alpha(E R \alpha)$ in cortical astrocytes impairs neurotrophic support in male and female rats. Endocrinology 154, 2101-2113. doi: 10.1210/en.2012-2046

Arnold, S., De Araújo, G. W., and Beyer, C. (2008). Gender-specific regulation of mitochondrial fusion and fission gene transcription and viability of cortical astrocytes by steroid hormones. J. Mol. Endocrinol. 41, 289-300. doi: 10.1677/JME-08-0085

Austad, S. N., and Fischer, K. E. (2016). Sex differences in lifespan. Cell Metab. 23, 1022-1033. doi: 10.1016/j.cmet.2016.05.019

Azcoitia, I., Sierra, A., Veiga, S., and Garcia-Segura, L. M. (2003). Aromatase expression by reactive astroglia is neuroprotective. Ann. N Y Acad. Sci. 1007, 298-305. doi: 10.1196/annals. 1286.028

Baeza, I., Alvarado, C., Ariznavarreta, C., Castillo, C., Tresguerres, J. A., and De la Fuente, M. (2008). Effect of growth hormone treatment on lymphocyte functions in old male rats. Neuroimmunomodulation 15, 279-284. doi: $10.1159 / 000156471$

Barja, G. (2004). Free radicals and aging. Trends Neurosci. 27, 595-600. doi: 10.1016/j.tins.2004.07.005

\section{AUTHOR CONTRIBUTIONS}

All authors listed, have made substantial, direct and intellectual contribution to the work, and approved it for publication.

\section{ACKNOWLEDGMENTS}

The authors gratefully acknowledge the financial support from different institutions. SZ was supported by a short-term EMBO fellowship, an ISN-CAEN grant and a mobility grant from University of Buenos Aires. TS was supported by a grant from the Velux Foundation to the Danish AgingResearch Center. RG was supported by a "Salvador de Madariaga" mobility grant from the Spanish Education Ministry and a grant from Complutense University.

Barron, A. M., Ji, B., Kito, S., Suhara, T., and Higuchi, M. (2017). Steroidogenic abnormalities in translocator protein knockout mice and significance in the aging male. Biochem. J. doi: 10.1042/BCJ20170645 [Epub ahead of print].

Barron, A. M., and Pike, C. J. (2012). Sex hormones, aging, and Alzheimer's disease. Front. Biosci. 4, 976-997. doi: 10.2741/e434

Basu, S., Je, G., and Kim, Y. S. (2015). Transcriptional mutagenesis by 8-oxodG in $\alpha$-synuclein aggregation and the pathogenesis of Parkinson's disease. Exp. Mol. Med. 47:e179. doi: 10.1038/emm.2015.54

Baudry, M., Bi, X., and Aguirre, C. (2013). Progesterone-estrogen interactions in synaptic plasticity and neuroprotection. Neuroscience 239, 280-294. doi: 10.1016/j.neuroscience.2012.10.051

Beal, M. F. (2005). Mitochondria take center stage in aging and neurodegeneration. Ann. Neurol. 58, 495-505. doi: 10.1002/ana.20624

Beauquis, J., Pavia, P., Pomilio, C., Vinuesa, A., Podlutskaya, N., Galvan, V., et al. (2013). Environmental enrichment prevents astroglial pathological changes in the hippocampus of APP transgenic mice, model of Alzheimer's disease. Exp. Neurol. 239, 28-37. doi: 10.1016/j.expneurol.2012.09.009

Bekinschtein, P., Cammarota, M., and Medina, J. H. (2014). BDNF and memory processing. Neuropharmacology 76, 677-683. doi: 10.1016/j.neuropharm.2013. 04.024

Bellanti, F., Matteo, M., Rollo, T., De Rosario, F., Greco, P., Vendemiale, G., et al. (2013). Sex hormones modulate circulating antioxidant enzymes: impact of estrogen therapy. Redox Biol. 1, 340-346. doi: 10.1016/j.redox.2013.05.003

Benedusi, V., Meda, C., Della Torre, S., Monteleone, G., Vegeto, E., and Maggi, A. (2012). A lack of ovarian function increases neuroinflammation in aged mice. Endocrinology 153, 2777-2788. doi: 10.1210/en.2011-1925

Berchtold, N. C., Cribbs, D. H., Coleman, P. D., Rogers, J., Head, E., Kim, R., et al. (2008). Gene expression changes in the course of normal brain aging are sexually dimorphic. Proc. Natl. Acad. Sci. U S A 105, 15605-15610. doi: 10.1073/pnas.0806883105

Bethea, C. L., Kohama, S. G., Reddy, A. P., and Urbanski, H. F. (2016). Ovarian steroids regulate gene expression in the dorsal raphe of old female macaques. Neurobiol. Aging 37, 179-191. doi: 10.1016/j.neurobiolaging.2015.10.004

Bimonte-Nelson, H. A., Francis, K. R., Umphlet, C. D., and Granholm, A. C. (2006). Progesterone reverses the spatial memory enhancements initiated by tonic and cyclic oestrogen therapy in middle-aged ovariectomized female rats. Eur. J. Neurosci. 24, 229-242. doi: 10.1111/j.1460-9568.2006.04867.x

Bimonte-Nelson, H. A., Nelson, M. E., and Granholm, A. C. (2004). Progesterone counteracts estrogen-induced increases in neurotrophins in the aged female rat brain. Neuroreport 15, 2659-2663. doi: 10.1097/00001756-200412030-00021

Boesch, P., Weber-Lotfi, F., Ibrahim, N., Tarasenko, V., Cosset, A., Paulus, F., et al. (2011). DNA repair in organelles: pathways, organization, regulation, relevance in disease and aging. Biochim. Biophys. Acta 1813, 186-200. doi: 10.1016/j. bbamcr.2010.10.002

Bonner, W. M., Redon, C. E., Dickey, J. S., Nakamura, A. J., Sedelnikova, O. A., Solier, S., et al. (2008). $\gamma \mathrm{H} 2 \mathrm{AX}$ and cancer. Nat. Rev. Cancer 8, 957-967. doi: $10.1038 / \operatorname{nrc} 2523$ 
Borrás, C., Sastre, J., García-Sala, D., Lloret, A., Pallardö, F. V., and Viña, J. (2003). Mitochondria from females exhibit higher antioxidant gene expression and lower oxidative damage than males. Free Radic. Biol. Med. 34, 546-552. doi: 10.1016/s0891-5849(02)01356-4

Boulay, F., and Perdiz, D. (2005). 17 $\beta$-estradiol modulates UVB-induced cellular responses in estrogen receptors positive human breast cancer cells. J. Photochem. Photobiol. B Biol. 81, 143-153. doi: 10.1016/j.jphotobiol. 2005.05.008

Boulware, M. I., Kordasiewicz, H., and Mermelstein, P. G. (2007). Caveolin proteins are essential for distinct effects of membrane estrogen receptors in neurons. J. Neurosci. 27, 9941-9950. doi: 10.1523/jneurosci.1647-07.2007

Bourque, M., Dluzen, D. E., and Di Paolo, T. (2009). Neuroprotective actions of sex steroids in Parkinson's disease. Front. Neuroendocrinol. 30, 142-157. doi: 10.1016/j.yfrne.2009.04.014

Bowen, C., Zheng, T., and Gelmann, E. P. (2015). NKX3.1 suppresses TMPRSS2-ERG gene rearrangement and mediates repair of androgen receptorinduced DNA damage. Cancer Res. 75, 2686-2698. doi: 10.1158/0008-5472. CAN-14-3387

Bradford, J., Shin, J. Y., Roberts, M., Wang, C. E., Sheng, G., Li, S., et al. (2010). Mutant huntingtin in glial cells exacerbates neurological symptoms of Huntington disease mice. J. Biol. Chem. 285, 10653-10661. doi: 10.1074/jbc. M109.083287

Brann, D. W., Dhandapani, K., Wakade, C., Mahesh, V. B., and Khan, M. M. (2007). Neurotrophic and neuroprotective actions of estrogen: basic mechanisms and clinical implications. Steroids 72, 381-405. doi: 10.1016/j. steroids.2007.02.003

Bregeon, D., Peignon, P. A., and Sarasin, A. (2009). Transcriptional mutagenesis induced by 8-oxoguanine in mammalian cells. PLoS Genet. 5:e1000577. doi: 10.1371 /journal.pgen.1000577

Brinton, R. D. (2008). The healthy cell bias of estrogen action: mitochondrial bioenergetics and neurological implications. Trends Neurosci. 31, 529-537. doi: 10.1016/j.tins.2008.07.003

Brinton, R. D. (2009). Estrogen-induced plasticity from cells to circuits: predictions for cognitive function. Trends Pharmacol. Sci. 30, 212-222. doi: 10.1016/j.tips.2008.12.006

Brinton, R. D., Thompson, R. F., Foy, M. R., Baudry, M., Wang, J., Finch, C. E., et al. (2008). Progesterone receptors: form and function in brain. Front. Neuroendocrinol. 29, 313-339. doi: 10.1016/j.yfrne.2008.02.001

Broe, M., Kril, J., and Halliday, G. M. (2004). Astrocytic degeneration relates to the severity of disease in frontotemporal dementia. Brain 127, 2214-2220. doi: 10.1093/brain/awh250

Bus, B. A., Tendolkar, I., Franke, B., de Graaf, J., den Heijer, M., Buitelaar, J. K., et al. (2012). Serum brain-derived neurotrophic factor: determinants and relationship with depressive symptoms in a community population of middle-aged and elderly people. World J. Biol. Psychiatry 13, 39-47. doi: 10.3109/15622975.2010.545187

Cabelof, D. C., Yanamadala, S., Raffoul, J. J., Guo, Z., Soofi, A., and Heydari, A. R. (2003). Caloric restriction promotes genomic stability by induction of base excision repair and reversal of its age-related decline. DNA Repair (Amst) 2, 295-307. doi: 10.1016/s1568-7864(02)00219-7

Cai, Y., Chew, C., Muñoz, F., and Sengelaub, D. R. (2017). Neuroprotective effects of testosterone metabolites and dependency on receptor action on the morphology of somatic motoneurons following the death of neighboring motoneurons. Dev. Neurobiol. 77, 691-707. doi: 10.1002/dneu.22445

Caldon, C. E. (2014). Estrogen signaling and the DNA damage response in hormone dependent breast cancers. Front. Oncol. 4:106. doi: 10.3389/fonc. 2014.00106

Calvo, J. A., Allocca, M., Fake, K. R., Muthupalani, S., Corrigan, J. J., Bronson, R. T., et al. (2016). Parpl protects against Aag-dependent alkylation-induced nephrotoxicity in a sex-dependent manner. Oncotarget 7, 44950-44965. doi: 10.18632/oncotarget.10440

Cantuti-Castelvetri, I., Lin, M. T., Zheng, K., Keller-McGandy, C. E., Betensky, R. A., Johns, D. R., et al. (2005). Somatic mitochondrial DNA mutations in single neurons and glia. Neurobiol. Aging 26, 1343-1355. doi: 10.1016/j.neurobiolaging.2004.11.008

Canugovi, C., Shamanna, R. A., Croteau, D. L., and Bohr, V. A. (2014). Base excision DNA repair levels in mitochondrial lysates of Alzheimer's disease. Neurobiol. Aging 35, 1293-1300. doi: 10.1016/j.neurobiolaging.2014.01.004
Cardona-Gómez, G. P., Mendez, P., DonCarlos, L. L., Azcoitia, I., and GarciaSegura, L. M. (2002). Interactions of estrogen and insulin-like growth factor-I in the brain: molecular mechanisms and functional implications. J. Steroid Biochem. Mol. Biol. 83, 211-217. doi: 10.1016/s0960-0760(02)00261-3

Carroll, J. C., Rosario, E. R., and Pike, C. J. (2008). Progesterone blocks estrogen neuroprotection from kainate in middle-aged female rats. Neurosci. Lett. 445, 229-232. doi: 10.1016/j.neulet.2008.09.010

Caruso, D., Pesaresi, M., Maschi, O., Giatti, S., Garcia-Segura, L. M., and Melcangi, R. C. (2010). Effect of short-and long-term gonadectomy on neuroactive steroid levels in the central and peripheral nervous system of male and female rats. J. Neuroendocrinol. 22, 1137-1147. doi: 10.1111/j.1365-2826. 2010.02064.x

Cerbai, F., Lana, D., Nosi, D., Petkova-Kirova, P., Zecchi, S., Brothers, H. M., et al. (2012). The neuron-astrocyte-microglia triad in normal brain ageing and in a model of neuroinflammation in the rat hippocampus. PLoS One 7:e45250. doi: 10.1371/journal.pone.0045250

Chakrabarti, S., Munshi, S., Banerjee, K., Thakurta, I. G., Sinha, M., and Bagh, M. B. (2011). Mitochondrial dysfunction during brain aging: role of oxidative stress and modulation by antioxidant supplementation. Aging Dis. 2, 242-256.

Chamniansawat, S., and Chongthammakun, S. (2012). A priming role of local estrogen on exogenous estrogen-mediated synaptic plasticity and neuroprotection. Exp. Mol. Med. 44, 403-411. doi: 10.3858/emm.2012. 44.6.046

Chapman, T. R., Barrientos, R. M., Ahrendsen, J. T., Hoover, J. M., Maier, S. F., and Patterson, S. L. (2012). Aging and infection reduce expression of specific brain-derived neurotrophic factor mRNAs in hippocampus. Neurobiol. Aging 33, 832.e1-832.e14. doi: 10.1016/j.neurobiolaging.2011.07.015

Chen, J. Q., Eshete, M., Alworth, W. L., and Yager, J. D. (2004). Binding of MCF-7 cell mitochondrial proteins and recombinant human estrogen receptors $\alpha$ and $\beta$ to human mitochondrial DNA estrogen response elements. J. Cell. Biochem. 93, 358-373. doi: 10.1002/jcb.20178

Christensen, A., and Pike, C. J. (2015). Menopause, obesity and inflammation: interactive risk factors for Alzheimer's disease. Front. Aging Neurosci. 7:130. doi: 10.3389/fnagi.2015.00130

Claypool, S. M., and Koehler, C. M. (2012). The complexity of cardiolipin in health and disease. Trends Biochem. Sci. 37, 32-41. doi: 10.1016/j.tibs.2011.09.003

Coffey, C. E., Lucke, J. F., Saxton, J. A., Ratcliff, G., Unitas, L. J., Billig, B., et al. (1998). Sex differences in brain aging: a quantitative magnetic resonance imaging study. Arch. Neurol. 55, 169-179. doi: 10.1001/archneur.55.2.169

Colciago, A., Casati, L., Negri-Cesi, P., and Celotti, F. (2015). Learning and memory: steroids and epigenetics. J. Steroid Biochem. Mol. Biol. 150, 64-85. doi: 10.1016/j.jsbmb.2015.02.008

Coppedè, F., and Migliore, L. (2015). DNA damage in neurodegenerative diseases. Mutat. Res. 776, 84-97. doi: 10.1016/j.mrfmmm.2014.11.010

Cotrina, M. L., and Nedergaard, M. (2002). Astrocytes in the aging brain. J. Neurosci. Res. 67, 1-10. doi: 10.1002/jnr.10121

Cui, J., Shen, Y., and Li, R. (2013). Estrogen synthesis and signaling pathways during aging: from periphery to brain. Trends Mol. Med. 19, 197-209. doi: 10.1016/j.molmed.2012.12.007

Cunningham, R. L., Singh, M., O’Bryant, S. E., Hall, J. R., and Barber, R. C. (2014). Oxidative stress, testosterone, and cognition among Caucasian and MexicanAmerican men with and without Alzheimer's disease. J. Alzheimers Dis. 40, 563-573. doi: 10.3233/JAD-131994

de Boer, J., and Hoeijmakers, J. H. (2000). Nucleotide excision repair and human syndromes. Carcinogenesis 21, 453-460. doi: 10.1093/carcin/21.3.453

De Nicola, A. F., Garay, L. I., Meyer, M., Guennoun, R., Sitruk-Ware, R., Schumacher, M., et al. (2017). Neurosteroidogenesis and progesterone antiinflammatory/neuroprotective effects. J. Neuroendocrinol. doi: 10.1111/jne. 12502 [Epub ahead of print].

De Nicola, A. F., Gonzalez Deniselle, M. C., Garay, L., Meyer, M., GargiuloMonachelli, G., Guennoun, R., et al. (2013). Progesterone protective effects in neurodegeneration and neuroinflammation. J. Neuroendocrinol. 25, 1095-1103. doi: 10.1111/jne.12043

De Nicola, A. F., Labombarda, F., Gonzalez Deniselle, M. C., Gonzalez, S. L. Garay, L., Meyer, M., et al. (2009). Progesterone neuroprotection in traumatic CNS injury and motoneuron degeneration. Front. Neuroendocrinol. 30, 173-187. doi: 10.1016/j.yfrne.2009.03.001 
Demonacos, C. V., Karayanni, N., Hatzoglou, E., Tsiriyiotis, C., Spandidos, D. A., and Sekeris, C. E. (1996). Mitochondrial genes as sites of primary action of steroid hormones. Steroids 61, 226-232. doi: 10.1016/0039-128x(96)00019-0

Dietrich, A. K., Humphreys, G. I., and Nardulli, A. M. (2013). 17ß-estradiol increases expression of the oxidative stress response and DNA repair protein apurinic endonuclease (Ape1) in the cerebral cortex of female mice following hypoxia. J. Steroid Biochem. Mol. Biol. 138, 410-420. doi: 10.1016/j.jsbmb.2013. 07.007

Ding, F., Yao, J., Zhao, L., Mao, Z., Chen, S., and Brinton, R. D. (2013). Ovariectomy induces a shift in fuel availability and metabolism in the hippocampus of the female transgenic model of familial Alzheimer's. PLoS One 8:e59825. doi: 10.1371/journal.pone.0059825

Dizdaroglu, M., Jaruga, P., Birincioglu, M., and Rodriguez, H. (2002). Free radicalinduced damage to DNA: mechanisms and measurement. Free Radic. Biol. Med. 32, 1102-1115. doi: 10.1016/S0891-5849(02)00826-2

Do Rego, J. L., Seong, J. Y., Burel, D., Leprince, J., Luu-The, V., Tsutsui, K., et al. (2009). Neurosteroid biosynthesis: enzymatic pathways and neuroendocrine regulation by neurotransmitters and neuropeptides. Front. Neuroendocrinol. 30, 259-301. doi: 10.1016/j.yfrne.2009.05.006

Dumitriu, D., Rapp, P. R., McEwen, B. S., and Morrison, J. H. (2010). Estrogen and the aging brain: an elixir for the weary cortical network. Ann. N Y Acad. Sci. 1204, 104-112. doi: 10.1111/j.1749-6632.2010.05529.x

El-Etr, M., Rame, M., Boucher, C., Ghoumari, A. M., Kumar, N., Liere, P., et al. (2015). Progesterone and nestorone promote myelin regeneration in chronic demyelinating lesions of corpus callosum and cerebral cortex. Glia 63, 104-117. doi: 10.1002/glia.22736

Evans, M. D., Butler, J. M., Nicoll, K., Cooke, M. S., and Lunec, J. (2003). 17 $\beta$-Oestradiol attenuates nucleotide excision repair. FEBS Lett. 535, 153-158. doi: 10.1016/s0014-5793(02)03898-x

Fang, M., Xia, F., Mahalingam, M., Virbasius, C. M., Wajapeyee, N., and Green, M. R. (2013). MEN1 is a melanoma tumor suppressor that preserves genomic integrity by stimulating transcription of genes that promote homologous recombination-directed DNA repair. Mol. Cell. Biol. 33, 2635-2647. doi: 10.1128/MCB.00167-13

Fleming, A. M., and Burrows, C. J. (2013). G-quadruplex folds of the human telomere sequence alter the site reactivity and reaction pathway of guanine oxidation compared to duplex DNA. Chem. Res. Toxicol. 26, 593-607. doi: $10.1021 / \mathrm{tx} 400028 \mathrm{y}$

Fortress, A. M., Kim, J., Poole, R. L., Gould, T. J., and Frick, K. M. (2014). 17ßEstradiol regulates histone alterations associated with memory consolidation and increases Bdnf promoter acetylation in middle-aged female mice. Learn. Mem. 21, 457-467. doi: 10.1101/lm.034033.113

Frick, K. M. (2009). Estrogens and age-related memory decline in rodents: what have we learned and where do we go from here? Horm. Behav. 55, 2-23. doi: 10.1016/j.yhbeh.2008.08.015

Gabbita, S. P., Lovell, M. A., and Markesbery, W. R. (1998). Increased nuclear DNA oxidation in the brain in Alzheimer's disease. J. Neurochem. 71, 2034-2040. doi: 10.1046/j.1471-4159.1998.71052034.x

Gaignard, P., Savouroux, S., Liere, P., Pianos, A., Thérond, P., Schumacher, M., et al. (2015). Effect of sex differences on brain mitochondrial function and its suppression by ovariectomy and in aged mice. Endocrinology 156, 2893-2904. doi: 10.1210/en.2014-1913

Gao, X., Smith, G. M., and Chen, J. (2009). Impaired dendritic development and synaptic formation of postnatal-born dentate gyrus granular neurons in the absence of brain-derived neurotrophic factor signaling. Exp. Neurol. 215, 178-190. doi: 10.1016/j.expneurol.2008.10.009

Garay, L., Gonzalez Deniselle, M. C., Lima, A., Roig, P., and De Nicola, A. F. (2007). Effects of progesterone in the spinal cord of a mouse model of multiple sclerosis. J. Steroid Biochem. Mol. Biol. 107, 228-237. doi: 10.1016/j.jsbmb.2007. 03.040

Garay, L., Gonzalez Deniselle, M. C., Meyer, M., Costa, J. J., Lima, A., Roig, P., et al. (2009). Protective effects of progesterone administration on axonal pathology in mice with experimental autoimmune encephalomyelitis. Brain Res. 1283, 177-185. doi: 10.1016/j.brainres.2009.04.057

García-Fernández, M., Delgado, G., Puche, J. E., González-Barón, S., and Castilla Cortazar, I. (2008). Low doses of insulin-like growth factor I improve insulin resistance, lipid metabolism, and oxidative damage in aging rats. Endocrinology 149, 2433-2442. doi: 10.1210/en.2007-1190
Garcia-Segura, L. M., Arévalo, M. A., and Azcoitia, I. (2010). Interactions of estradiol and insulin-like growth factor-I signalling in the nervous system: new advances. Prog. Brain Res. 181, 251-272. doi: 10.1016/s0079-6123(08) 81014-x

Garcia-Segura, L. M., Cardona-Gomez, P., Naftolin, F., and Chowen, J. A. (1998). Estradiol upregulates Bcl-2 expression in adult brain neurons. Neuroreport 9, 593-597. doi: 10.1097/00001756-199803090-00006

Ghoumari, A. M., Baulieu, E. E., and Schumacher, M. (2005). Progesterone increases oligodendroglial cell proliferation in rat cerebellar slice cultures. Neuroscience 135, 47-58. doi: 10.1016/j.neuroscience.2005.05.023

Gibbs, R. B. (1998). Levels of trkA and BDNF mRNA, but not NGF mRNA, fluctuate across the estrous cycle and increase in response to acute hormone replacement. Brain Res. 787, 259-268. doi: 10.1016/S0006-8993(97)01511-4

Gillies, G. E., Pienaar, I. S., Vohra, S., and Qamhawi, Z. (2014). Sex differences in Parkinson's disease. Front. Neuroendocrinol. 35, 370-384. doi: 10.1016/j.yfrne. 2014.02.002

Golden, T. R., Hinerfeld, D. A., and Melov, S. (2002). Oxidative stress and aging: beyond correlation. Aging Cell 1, 117-123. doi: 10.1046/j.1474-9728. 2002.00015.x

Gould, E., Woolley, C. S., Frankfurt, M., and McEwen, B. S. (1990). Gonadal steroids regulate dendritic spine density in hippocampal pyramidal cells in adulthood. J. Neurosci. 10, 1286-1291.

Graham, J. D., and Clarke, C. L. (1997). Physiological action of progesterone in target tissues. Endocr. Rev. 18, 502-519. doi: 10.1210/er.18.4.502

Gredilla, R. (2010). DNA damage and base excision repair in mitochondria and their role in aging. J. Aging Res. 2011:257093. doi: 10.4061/2011/257093

Gredilla, R., Bohr, V. A., and Stevnsner, T. (2010a). Mitochondrial DNA repair and association with aging-an update. Exp. Gerontol. 45, 478-488. doi: 10.1016/j. exger.2010.01.017

Gredilla, R., Garm, C., Holm, R., Bohr, V. A., and Stevnsner, T. (2010b). Differential age-related changes in mitochondrial DNA repair activities in mouse brain regions. Neurobiol. Aging 31, 993-1002. doi: 10.1016/j. neurobiolaging.2008.07.004

Gredilla, R., Weissman, L., Yang, J. L., Bohr, V. A., and Stevnsner, T. (2012). Mitochondrial base excision repair in mouse synaptosomes during normal aging and in a model of Alzheimer's disease. Neurobiol. Aging 33, 694-707. doi: 10.1016/j.neurobiolaging.2010.06.019

Grimm, A., Friedland, K., and Eckert, A. (2016a). Mitochondrial dysfunction: the missing link between aging and sporadic Alzheimer's disease. Biogerontology 17, 281-296. doi: 10.1007/s10522-015-9618-4

Grimm, A., Mensah-Nyagan, A. G., and Eckert, A. (2016b). Alzheimer, mitochondria and gender. Neurosci. Biobehav. Rev. 67, 89-101. doi: 10.1016/j. neubiorev.2016.04.012

Grossman, L., and Wei, Q. (1995). DNA repair and epidemiology of basal cell carcinoma. Clin. Chem. 41, 1854-1863.

Gyenes, A., Hoyk, Z., Csakvari, E., Siklos, L., and Parducz, A. (2010). 17ß-estradiol attenuates injury-induced microglia activation in the oculomotor nucleus. Neuroscience 171, 677-682. doi: 10.1016/j.neuroscience.2010.09.033

Habib, P., and Beyer, C. (2015). Regulation of brain microglia by female gonadal steroids. J. Steroid Biochem. Mol. Biol. 146, 3-14. doi: 10.1016/j.jsbmb. 2014.02.018

Habib, S. L., Yadav, A., Kidane, D., Weiss, R. H., and Liang, S. (2016). Novel protective mechanism of reducing renal cell damage in diabetes: activation AMPK by AICAR increased NRF2/OGG1 proteins and reduced oxidative DNA damage. Cell Cycle 15, 3048-3059. doi: 10.1080/15384101.2016.1231259

Hara, Y., Waters, E. M., McEwen, B. S., and Morrison, J. H. (2015). Estrogen effects on cognitive and synaptic health over the lifecourse. Physiol. Rev. 95, 785-807. doi: 10.1152 physrev.00036.2014

Hara, Y., Yuk, F., Puri, R., Janssen, W. G., Rapp, P. R., and Morrison, J. H. (2014). Presynaptic mitochondrial morphology in monkey prefrontal cortex correlates with working memory and is improved with estrogen treatment. Proc. Natl. Acad. Sci. U S A 111, 486-491. doi: 10.1073/pnas.1311310110

Heldt, S. A., Stanek, L., Chhatwal, J. P., and Ressler, K. J. (2007). Hippocampusspecific deletion of BDNF in adult mice impairs spatial memory and extinction of aversive memories. Mol. Psychiatry 12, 656-670. doi: 10.1038/sj.mp.4001957

Hellner, K., Walther, T., Schubert, M., and Albrecht, D. (2005). Angiotensin-(1-7) enhances LTP in the hippocampus through the G-protein-coupled receptor Mas. Mol. Cell. Neurosci. 29, 427-435. doi: 10.1016/j.mcn.2005.03.012 
Herrick, S. P., Waters, E. M., Drake, C. T., McEwen, B. S., and Milner, T. A. (2006). Extranuclear estrogen receptor $\beta$ immunoreactivity is on doublecortincontaining cells in the adult and neonatal rat dentate gyrus. Brain Res. 1121, 46-58. doi: 10.1016/j.brainres.2006.08.084

Hollensworth, S. B., Shen, C., Sim, J. E., Spitz, D. R., Wilson, G. L., and Ledoux, S. P. (2000). Glial cell type-specific responses to menadione-induced oxidative stress. Free Radic. Biol. Med. 28, 1161-1174. doi: 10.1016/s08915849(00)00214-8

Huang, R., and Poduslo, S. E. (2006). CYP19 haplotypes increase risk for Alzheimer's disease. J. Med. Genet. 43:e42. doi: 10.1136/jmg.2005.039461

Huang, Y. H., and Zhang, Q. H. (2010). Genistein reduced the neural apoptosis in the brain of ovariectomised rats by modulating mitochondrial oxidative stress. Br. J. Nutr. 104, 1297-1303. doi: 10.1017/s0007114510002291

Huffman, J., Hoffmann, C., and Taylor, G. T. (2017). Integrating insulin-like growth factor 1 and sex hormones into neuroprotection: implications for diabetes. World J. Diabetes 8, 45-55. doi: 10.4239/wjd.v8.i2.45

Hwang, Y. P., and Jeong, H. G. (2010). Ginsenoside Rb1 protects against 6hydroxydopamine-induced oxidative stress by increasing heme oxygenase-1 expression through an estrogen receptor-related PI3K/Akt/Nrf2-dependent pathway in human dopaminergic cells. Toxicol. Appl. Pharmacol. 242, 18-28. doi: 10.1016/j.taap.2009.09.009

Iida, T., Furuta, A., Nishioka, K., Nakabeppu, Y., and Iwaki, T. (2002). Expression of 8-oxoguanine DNA glycosylase is reduced and associated with neurofibrillary tangles in Alzheimer's disease brain. Acta Neuropathol. 103, 20-25. doi: $10.1007 / \mathrm{s} 004010100418$

Iivonen, S., Corder, E., Lehtovirta, M., Helisalmi, S., Mannermaa, A., Vepsäläinen, S., et al. (2004). Polymorphisms in the CYP19 gene confer increased risk for Alzheimer disease. Neurology 62, 1170-1176. doi: 10.1212/01. WNL.0000118208.16939.60

Imam, S. Z., Karahalil, B., Hogue, B. A., Souza-Pinto, N. C., and Bohr, V. A. (2006). Mitochondrial and nuclear DNA-repair capacity of various brain regions in mouse is altered in an age-dependent manner. Neurobiol. Aging 27, 1129-1136. doi: 10.1016/j.neurobiolaging.2005.06.002

Irwin, R. W., Yao, J., Ahmed, S. S., Hamilton, R. T., Cadenas, E., and Brinton, R. D. (2011). Medroxyprogesterone acetate antagonizes estrogen up-regulation of brain mitochondrial function. Endocrinology 152, 556-567. doi: 10.1210/en. 2010-1061

Irwin, R. W., Yao, J., To, J., Hamilton, R. T., Cadenas, E., and Brinton, R. D. (2012). Selective oestrogen receptor modulators differentially potentiate brain mitochondrial function. J. Neuroendocrinol. 24, 236-248. doi: 10.1111/j.13652826.2011.02251.x

Ishihara, Y., Fujitani, N., Sakurai, H., Takemoto, T., Ikeda-Ishihara, N., Mori-Yasumoto, K., et al. (2016). Effects of sex steroid hormones and their metabolites on neuronal injury caused by oxygen-glucose deprivation/reoxygenation in organotypic hippocampal slice cultures. Steroids 113, 71-77. doi: 10.1016/j.steroids.2016.06.004

Iyama, T., and Wilson, D. M. III. (2013). DNA repair mechanisms in dividing and non-dividing cells. DNA Repair 12, 620-636. doi: 10.1016/j.dnarep.2013. 04.015

Jack, C. R. Jr., Wiste, H. J., Weigand, S. D., Knopman, D. S., Vemuri, P., Mielke, M. M., et al. (2015). Age, sex, and APOE $\varepsilon 4$ effects on memory, brain structure, and $\beta$-amyloid across the adult life span. JAMA Neurol. 72, 511-519. doi: 10.1001/jamaneurol.2014.4821

Jacome, L. F., Barateli, K., Buitrago, D., Lema, F., Frankfurt, M., and Luine, V. N. (2016). Gonadal hormones rapidly enhance spatial memory and increase hippocampal spine density in male rats. Endocrinology 157, 1357-1362. doi: 10.1210/en.2015-1959

Jayakumar, S., Pal, D., and Sandur, S. K. (2015). Nrf2 facilitates repair of radiation induced DNA damage through homologous recombination repair pathway in a ROS independent manner in cancer cells. Mutat. Res. 779, 33-45. doi: 10.1016/j.mrfmmm.2015.06.007

Jeppesen, D. K., Bohr, V. A., and Stevnsner, T. (2011). DNA repair deficiency in neurodegeneration. Prog. Neurobiol. 94, 166-200. doi: 10.1016/j.pneurobio. 2011.04.013

Jia, J. X., Cui, C. L., Yan, X. S., Zhang, B. F., Song, W., Huo, D. S., et al. (2016). Effects of testosterone on synaptic plasticity mediated by androgen receptors in male SAMP8 mice. J. Toxicol. Environ. Health Part A 79, 849-855. doi: $10.1080 / 15287394.2016 .1193113$
Jia, J., Kang, L., Li, S., Geng, D., Fan, P., Wang, L., et al. (2013). Amelioratory effects of testosterone treatment on cognitive performance deficits induced by soluble A $\beta 1-42$ oligomers injected into the hippocampus. Horm. Behav. 64, 477-486. doi: 10.1016/j.yhbeh.2013.08.002

Jiricny, J. (2006). The multifaceted mismatch-repair system. Nat. Rev. Mol. Cell Biol. 7, 335-346. doi: 10.1038/nrm1907

Johri, A., and Beal, M. F. (2012). Mitochondrial dysfunction in neurodegenerative diseases. J. Pharmacol. Exp. Ther. 342, 619-630. doi: 10.1124/jpet.112. 192138

Kang, D., Kim, S. H., and Hamasaki, N. (2007). Mitochondrial transcription factor A (TFAM): roles in maintenance of mtDNA and cellular functions. Mitochondrion 7, 39-44. doi: 10.1016/j.mito.2006.11.017

Katyal, S., Lee, Y., Nitiss, K. C., Downing, S. M., Li, Y., Shimada, M., et al. (2014). Aberrant topoisomerase-1 DNA lesions are pathogenic in neurodegenerative genome instability syndromes. Nat. Neurosci. 17, 813-821. doi: 10.1038/ nn. 3715

Kaur, P., Jodhka, P. K., Underwood, W. A., Bowles, C. A., de Fiebre, N. C., de Fiebre, C. M., et al. (2007). Progesterone increases brain-derived neuroptrophic factor expression and protects against glutamate toxicity in a mitogen-activated protein kinase- and phosphoinositide- 3 kinase-dependent manner in cerebral cortical explants. J. Neurosci. Res. 85, 2441-2449. doi: 10.1002/jnr.21370

Kelly, J. F., Bienias, J. L., Shah, A., Meeke, K. A., Schneider, J. A., Soriano, E., et al. (2008). Levels of estrogen receptors $\alpha$ and $\beta$ in frontal cortex of patients with Alzheimer's disease: relationship to Mini-Mental State Examination scores. Curr. Alzheimer Res. 5, 45-51. doi: 10.2174/156720508783884611

Kelly, M. J., and Levin, E. R. (2001). Rapid actions of plasma membrane estrogen receptors. Trends Endocrinol. Metab. 12, 152-156. doi: 10.1016/s10432760(01)00377-0

Kemper, M. F., Stirone, C., Krause, D. N., Duckles, S. P., and Procaccio, V. (2014). Genomic and non-genomic regulation of PGC1 isoforms by estrogen to increase cerebral vascular mitochondrial biogenesis and reactive oxygen species protection. Eur. J. Pharmacol. 723, 322-329. doi: 10.1016/j.ejphar.2013.11.009

Kemper, M. F., Zhao, Y., Duckles, S. P., and Krause, D. N. (2013). Endogenous ovarian hormones affect mitochondrial efficiency in cerebral endothelium via distinct regulation of PGC-1 isoforms. J. Cereb. Blood Flow Metab. 33, 122-128. doi: $10.1038 / \mathrm{jcbfm} .2012 .159$

Kerr, D. S., Bevilaqua, L. R., Bonini, J. S., Rossato, J. I., Köhler, C. A., Medina, J. H., et al. (2005). Angiotensin II blocks memory consolidation through an AT2 receptor-dependent mechanism. Psychopharmacology 179, 529-535. doi: 10.1007/s00213-004-2074-5

Kireev, R. A., Vara, E., Vina, J., and Tresguerres, J. A. (2014). Melatonin and oestrogen treatments were able to improve neuroinflammation and apoptotic processes in dentate gyrus of old ovariectomized female rats. Age 36:9707. doi: $10.1007 /$ s11357-014-9707-3

Kisby, G. E., Kohama, S. G., Olivas, A., Churchwell, M., Doerge, D., Spangler, E., et al. (2010). Effect of caloric restriction on base-excision repair (BER) in the aging rat brain. Exp. Gerontol. 45, 208-216. doi: 10.1016/j.exger.2009.12.003

Kiss, A., Delattre, A. M., Pereira, S. I., Carolino, R. G., Szawka, R. E., AnselmoFranci, J. A., et al. (2012). 17 $\beta$-estradiol replacement in young, adult and middle-aged female ovariectomized rats promotes improvement of spatial reference memory and an antidepressant effect and alters monoamines and BDNF levels in memory- and depression-related brain areas. Behav. Brain Res. 227, 100-108. doi: 10.1016/j.bbr.2011.10.047

Klinge, C. M. (2017). Estrogens regulate life and death in mitochondria. J. Bioenerg. Biomembr. 49, 307-324. doi: 10.1007/s10863-017-9704-1

Kovtun, I. V., Liu, Y., Bjoras, M., Klungland, A., Wilson, S. H., and McMurray, C. T. (2007). OGG1 initiates age-dependent CAG trinucleotide expansion in somatic cells. Nature 447, 447-452. doi: 10.1038/nature05778

Kowal, S. L., Dall, T. M., Chakrabarti, R., Storm, M. V., and Jain, A. (2013). The current and projected economic burden of Parkinson's disease in the United States. Mov. Disord. 28, 311-318. doi: 10.1002/mds.25292

Kujoth, G. C., Bradshaw, P. C., Haroon, S., and Prolla, T. A. (2007). The role of mitochondrial DNA mutations in mammalian aging. PLoS Genet. 3:e24. doi: 10.1371/journal.pgen.0030024

Kulijewicz-Nawrot, M., Verkhratsky, A., Chvátal, A., Syková, E., and Rodríguez, J. J. (2012). Astrocytic cytoskeletal atrophy in the medial prefrontal cortex of a triple transgenic mouse model of Alzheimer's disease. J. Anat. 221, 252-262. doi: $10.1111 /$ j.1469-7580.2012.01536.x 
Labandeira-Garcia, J. L., Rodríguez-Perez, A. I., Garrido-Gil, P., RodriguezPallares, J., Lanciego, J. L., and Guerra, M. J. (2017). Brain reninangiotensin system and microglial polarization: implications for aging and neurodegeneration. Front. Aging Neurosci. 9:129. doi: 10.3389/fnagi.2017. 00129

Labandeira-Garcia, J. L., Rodríguez-Perez, A. I., Valenzuela, R., CostaBesada, M. A., and Guerra, M. J. (2016). Menopause and Parkinson's disease. Interaction between estrogens and brain renin-angiotensin system in dopaminergic degeneration. Front. Neuroendocrinol. 43, 44-59. doi: 10.1016/j. yfrne.2016.09.003

Leclère, R., Torregrosa-Muñumer, R., Kireev, R., García, C., Vara, E., Tresguerres, J. A., et al. (2013). Effect of estrogens on base excision repair in brain and liver mitochondria of aged female rats. Biogerontology 14, 383-394. doi: $10.1007 / \mathrm{s} 10522-013-9431-\mathrm{x}$

Lei, D. L., Long, J. M., Hengemihle, J., O’Neill, J., Manaye, K. F., Ingram, D. K., et al. (2003). Effects of estrogen and raloxifene on neuroglia number and morphology in the hippocampus of aged female mice. Neuroscience 121, 659-666. doi: 10.1016/s0306-4522(03)00245-8

Leranth, C., Petnehazy, O., and MacLusky, N. J. (2003). Gonadal hormones affect spine synaptic density in the CA1 hippocampal subfield of male rats. J. Neurosci. 23, 1588-1592.

Li, L., Chen, J., Sun, S., Zhao, J., Dong, X., and Wang, J. (2017). Effects of estradiol on autophagy and Nrf-2/ARE signals after cerebral ischemia. Cell. Physiol. Biochem. 41, 2027-2036. doi: 10.1159/000475433

Li, R., He, P., Cui, J., Staufenbiel, M., Harada, N., and Shen, Y. (2013). Brain endogenous estrogen levels determine responses to estrogen replacement therapy via regulation of BACE1 and NEP in female Alzheimer's transgenic mice. Mol. Neurobiol. 47, 857-867. doi: 10.1007/s12035-012-8377-3

Li, S., Kang, L., Zhang, Y., Feng, B., Du, J., and Cui, H. (2015). Detecting the presence of hippocampus membrane androgen receptors in male SAMP8 mice and their induced synaptic plasticity. Mol. Cell. Endocrinol. 414, 82-90. doi: 10.1016/j.mce.2015.07.005

Li, M., Masugi-Tokita, M., Takanami, K., Yamada, S., and Kawata, M. (2012). Testosterone has sublayer-specific effects on dendritic spine maturation mediated by BDNF and PSD-95 in pyramidal neurons in the hippocampus CA1 area. Brain Res. 1484, 76-84. doi: 10.1016/j.brainres.2012.09.028

Li, M. X., Shan, J. L., Wang, D., He, Y., Zhou, Q., Xia, L., et al. (2012). Human apurinic/apyrimidinic endonuclease 1 translocalizes to mitochondria after photodynamic therapy and protects cells from apoptosis. Cancer Sci. 103, 882-888. doi: 10.1111/j.1349-7006.2012.02239.x

Li, R., and Singh, M. (2014). Sex differences in cognitive impairment and Alzheimer's disease. Front. Neuroendocrinol. 35, 385-403. doi: 10.1016/j.yfrne. 2014.01.002

Lillenes, M. S., Espeseth, T., Støen, M., Lundervold, A. J., Frye, S. A., Rootwelt, H., et al. (2011). DNA base excision repair gene polymorphisms modulate human cognitive performance and decline during normal life span. Mech. Ageing Dev. 132, 449-458. doi: 10.1016/j.mad.2011.08.002

Lillenes, M. S., Støen, M., Günther, C. C., Selnes, P., Stenset, V. T., Espeseth, T., et al. (2017). Mitochondrial transcription factor A (TFAM) rs1937 and AP endonuclease 1 (APE1) rs1130409 alleles are associated with reduced cognitive performance. Neurosci. Lett. 645, 46-52. doi: 10.1016/j.neulet.2017.02.062

Lindahl, T. (1993). Instability and decay of the primary structure of DNA. Nature 362, 709-715. doi: $10.1038 / 362709 \mathrm{a} 0$

Liu, P., and Demple, B. (2010). DNA repair in mammalian mitochondria: much more than we thought? Environ. Mol. Mutagen. 51, 417-426. doi: $10.1002 / \mathrm{em} .20576$

Lovell, M. A., and Markesbery, W. R. (2007). Oxidative DNA damage in mild cognitive impairment and late-stage Alzheimer's disease. Nucleic Acids Res. 35, 7497-7504. doi: 10.1093/nar/gkm821

Lovell, M. A., Xie, C., and Markesbery, W. R. (2000). Decreased base excision repair and increased helicase activity in Alzheimer's disease brain. Brain Res. 855, 116-123. doi: 10.1016/s0006-8993(99)02335-5

Lu, J. Y., Jin, P., Gao, W., Wang, D. Z., and Sheng, J. Q. (2017). Estrogen enhances mismatch repair by induction of MLH1 expression via estrogen receptor- $\beta$. Oncotarget 8, 38767-38779. doi: 10.18632/oncotarget.16351

Lu, H., Ma, K., Jin, L., Zhu, H., and Cao, R. (2018). 17ß-estradiol rescues damages following traumatic brain injury from molecule to behavior in mice. J. Cell. Physiol. 233, 1712-1722. doi: 10.1002/jcp.26083
Lu, T., Pan, Y., Kao, S. Y., Li, C., Kohane, I., Chan, J., et al. (2004). Gene regulation and DNA damage in the ageing human brain. Nature 429, 883-891. doi: 10.1038/nature02661

Lu, J., Xu, Y., Hu, W., Gao, Y., Ni, X., Sheng, H., et al. (2014). Exercise ameliorates depression-like behavior and increases hippocampal BDNF level in ovariectomized rats. Neurosci. Lett. 573, 13-18. doi: 10.1016/j.neulet.2014. 04.053

Luchetti, S., Bossers, K., Van De Bilt, S., Agrapart, V., Morales, R. R., Frajese, G. V., et al. (2011). Neurosteroid biosynthetic pathways changes in prefrontal cortex in Alzheimer's disease. Neurobiol. Aging 32, 1964-1976. doi: 10.1016/j. neurobiolaging.2009.12.014

Lynch, A. M., Murphy, K. J., Deighan, B. F., O’Reilly, J. A., Gun'ko, Y. K., Cowley, T. R., et al. (2010). The impact of glial activation in the aging brain. Aging Dis. 1, 262-278.

Maclusky, N. J., Hajszan, T., Prange-Kiel, J., and Leranth, C. (2006). Androgen modulation of hippocampal synaptic plasticity. Neuroscience 138, 957-965. doi: 10.1016/j.neuroscience.2005.12.054

Maki, P. M., and Resnick, S. M. (2000). Longitudinal effects of estrogen replacement therapy on PET cerebral blood flow and cognition. Neurobiol. Aging 21, 373-383. doi: 10.1016/s0197-4580(00)00123-8

Mandal, P. K., Tripathi, M., and Sugunan, S. (2012). Brain oxidative stress: detection and mapping of anti-oxidant marker 'Glutathione' in different brain regions of healthy male/female, MCI and Alzheimer patients using non-invasive magnetic resonance spectroscopy. Biochem. Biophys. Res. Commun. 417, 43-48. doi: 10.1016/j.bbrc.2011.11.047

Mangold, C. A., Wronowski, B., Du, M., Masser, D. R., Hadad, N., Bixler, G. V., et al. (2017). Sexually divergent induction of microglial-associated neuroinflammation with hippocampal aging. J. Neuroinflammation 14:141. doi: 10.1186/s12974-017-0920-8

Marin-Husstege, M., Muggironi, M., Raban, D., Skoff, R. P., and CasacciaBonnefil, P. (2004). Oligodendrocyte progenitor proliferation and maturation is differentially regulated by male and female sex steroid hormones. Dev. Neurosci. 26, 245-254. doi: 10.1159/000082141

May, M. (2016). Sex on the brain: unraveling the differences between women and men in neurodegenerative disease. Nat. Med. 22, 1370-1372. doi: $10.1038 / \mathrm{nm} 1216-1370$

McCullough, L. D., Blizzard, K., Simpson, E. R., Oz, O. K., and Hurn, P. D. (2003). Aromatase cytochrome P450 and extragonadal estrogen play a role in ischemic neuroprotection. J. Neurosci. 23, 8701-8705.

McDevitt, M. A., Glidewell-Kenney, C., Jimenez, M. A., Ahearn, P. C., Weiss, J., Jameson, J. L., et al. (2008). New insights into the classical and non-classical actions of estrogen: evidence from estrogen receptor knock-out and knock-in mice. Mol. Cell. Endocrinol. 290, 24-30. doi: 10.1016/j.mce.2008.04.003

McEwen, B. S., and Milner, T. A. (2007). Hippocampal formation: shedding light on the influence of sex and stress on the brain. Brain Res. Rev. 55, 343-355. doi: 10.1016/j.brainresrev.2007.02.006

McEwen, B. S., and Milner, T. A. (2017). Understanding the broad influence of sex hormones and sex differences in the brain. J. Neurosci. Res. 95, 24-39. doi: 10.1002/jnr.23809

McKinnon, P. J. (2016). Topoisomerases and the regulation of neural function. Nat. Rev. Neurosci. 17, 673-679. doi: 10.1038/nrn.2016.101

McLachlan, R. I., Tempel, B. L., Miller, M. A., Bicknell, J. N., Bremner, W. J., and Dorsa, D. M. (1991). Androgen receptor gene expression in the rat central nervous system: evidence for two mRNA transcripts. Mol. Cell. Neurosci. 2, 117-122. doi: 10.1016/1044-7431(91)90003-7

Melcangi, R. C., Giatti, S., Calabrese, D., Pesaresi, M., Cermenati, G., Mitro, N., et al. (2014). Levels and actions of progesterone and its metabolites in the nervous system during physiological and pathological conditions. Prog. Neurobiol. 113, 56-69. doi: 10.1016/j.pneurobio.2013.07.006

Melov, S. (2004). Modeling mitochondrial function in aging neurons. Trends Neurosci. 27, 601-606. doi: 10.1016/j.tins.2004.08.004

Mena, M. A., and García de Yébenes, J. (2008). Glial cells as players in parkinsonism: the "good," the "bad," and the "mysterious" glia. Neuroscientist 14, 544-560. doi: 10.1177/1073858408322839

Meydan, S., Kus, I., Tas, U., Ogeturk, M., Sancakdar, E., Dabak, D. O., et al. (2010). Effects of testosterone on orchiectomy-induced oxidative damage in the rat hippocampus. J. Chem. Neuroanat. 40, 281-285. doi: 10.1016/j.jchemneu. 2010.07.006 
Miller, V. M., and Harman, S. M. (2017). An update on hormone therapy in postmenopausal women: mini-review for the basic scientist. Am. J. Physiol. Heart Circ. Physiol. 313, H1013-H1021. doi: 10.1152/ajpheart.00383.2017

Milner, T. A., Ayoola, K., Drake, C. T., Herrick, S. P., Tabori, N. E., McEwen, B. S., et al. (2005). Ultrastructural localization of estrogen receptor $\beta$ immunoreactivity in the rat hippocampal formation. J. Comp. Neurol. 491, 81-95. doi: 10.1002/cne.20724

Milner, T. A., Lubbers, L. S., Alves, S. E., and McEwen, B. S. (2008). Nuclear and extranuclear estrogen binding sites in the rat forebrain and autonomic medullary areas. Endocrinology 149, 3306-3312. doi: 10.1210/en.2008-0307

Mitra, S., Izumi, T., Boldogh, I., Bhakat, K. K., Chattopadhyay, R., and Szczesny, B. (2007). Intracellular trafficking and regulation of mammalian AP-endonuclease 1 (APE1), an essential DNA repair protein. DNA Repair (Amst) 6, 461-469. doi: 10.1016/j.dnarep.2006.10.010

Mo, M. S., Li, H. B., Wang, B. Y., Wang, S. L., Zhu, Z. L., and Yu, X. R. (2013). PI3K/Akt and NF-kappaB activation following intravitreal administration of $17 \beta$-estradiol: neuroprotection of the rat retina from light-induced apoptosis. Neuroscience 228, 1-12. doi: 10.1016/j.neuroscience.2012.10.002

Monteiro-Cardoso, V. F., Oliveira, M. M., Melo, T., Domingues, M. R., Moreira, P. I., Ferreiro, E., et al. (2015). Cardiolipin profile changes are associated to the early synaptic mitochondrial dysfunction in Alzheimer's disease. J. Alzheimers Dis. 43, 1375-1392. doi: 10.3233/JAD141002

Morrison, J. H., Brinton, R. D., Schmidt, P. J., and Gore, A. C. (2006). Estrogen, menopause, and the aging brain: how basic neuroscience can inform hormone therapy in women. J. Neurosci. 26, 10332-10348. doi: 10.1523/JNEUROSCI. 3369-06.2006

Muslimovic, A., Ismail, I. H., Gao, Y., and Hammarsten, O. (2008). An optimized method for measurement of $\gamma-\mathrm{H} 2 \mathrm{AX}$ in blood mononuclear and cultured cells. Nat. Protoc. 3, 1187-1193. doi: 10.1038/nprot.2008.93

Naugle, M. M., Nguyen, L. T., Merceron, T. K., Filardo, E., Janssen, W. G., Morrison, J. H., et al. (2014). G-protein coupled estrogen receptor, estrogen receptor $\alpha$, and progesterone receptor immunohistochemistry in the hypothalamus of aging female rhesus macaques given long-term estradiol treatment. J. Exp. Zool. A Ecol. Genet. Physiol. 321, 399-414. doi: 10.1002/ jez.1871

Navarro, A., Lopez-Cepero, J. M., Bandez, M. J., Sanchez-Pino, M. J., Gomez, C., Cadenas, E., et al. (2008). Hippocampal mitochondrial dysfunction in rat aging. Am. J. Physiol. Regul. Integr. Comp. Physiol. 294, R501-R509. doi: 10.1152/ajpregu.00492.2007

Nilsen, J., and Diaz Brinton, R. (2003). Mechanism of estrogen-mediated neuroprotection: regulation of mitochondrial calcium and Bcl-2 expression. Proc. Natl. Acad. Sci. U S A 100, 2842-2847. doi: 10.1073/pnas.0438 041100

Nilsen, J., Irwin, R. W., Gallaher, T. K., and Brinton, R. D. (2007). Estradiol in vivo regulation of brain mitochondrial proteome. J. Neurosci. 27, 14069-14077. doi: 10.1523/JNEUROSCI.4391-07.2007

Nissen, J. C. (2017). Microglial function across the spectrum of age and gender. Int. J. Mol. Sci. 18:E561. doi: 10.3390/ijms18030561

Nilsson, S., Mäkelä, S., Treuter, E., Tujague, M., Thomsen, J., Andersson, G., et al. (2001). Mechanisms of estrogen action. Physiol. Rev. 81, 1535-1565. doi: 10.1152/physrev.2001.81.4.1535

Noorbakhsh, F., Baker, G. B., and Power, C. (2014). Allopregnanolone and neuroinflammation: a focus on multiple sclerosis. Front. Cell. Neurosci. 8:134. doi: $10.3389 /$ fncel.2014.00134

Oddo, S., Caccamo, A., Shepherd, J. D., Murphy, M. P., Golde, T. E., Kayed, R., et al. (2003). Triple-transgenic model of Alzheimer's disease with plaques and tangles: intracellular $A \beta$ and synaptic dysfunction. Neuron 39, 409-421. doi: 10.1016/S0896-6273(03)00434-3

Olabarria, M., Noristani, H. N., Verkhratsky, A., and Rodríguez, J. J. (2011). Age-dependent decrease in glutamine synthetase expression in the hippocampal astroglia of the triple transgenic Alzheimer's disease mouse model: mechanism for deficient glutamatergic transmission? Mol. Neurodegener. 6:55. doi: 10.1186/1750-1326-6-55

Overk, C. R., Lu, P. Y., Wang, Y. T., Choi, J., Shaw, J. W., Thatcher, G. R., et al. (2012). Effects of aromatase inhibition versus gonadectomy on hippocampal complex amyloid pathology in triple transgenic mice. Neurobiol. Dis. 45, 479-487. doi: 10.1016/j.nbd.2011.08.035
Pamplona, R. (2008). Membrane phospholipids, lipoxidative damage and molecular integrity: a causal role in aging and longevity. Biochim. Biophys. Acta 1777, 1249-1262. doi: 10.1016/j.bbabio.2008.07.003

Pan, W., Han, S., Kang, L., Li, S., Du, J., and Cui, H. (2016). Effects of dihydrotestosterone on synaptic plasticity of the hippocampus in mild cognitive impairment male SAMP8 mice. Exp. Ther. Med. 12, 1455-1463. doi: 10.3892/etm.2016.3470

Paradies, G., Petrosillo, G., Paradies, V., and Ruggiero, F. M. (2011). Mitochondrial dysfunction in brain aging: role of oxidative stress and cardiolipin. Neurochem. Int. 58, 447-457. doi: 10.1016/j.neuint.2010.12.016

Paris, J. J., Walf, A. A., and Frye, C. A. (2011). II. Cognitive performance of middle-aged female rats is influenced by capacity to metabolize progesterone in the prefrontal cortex and hippocampus. Brain Res. 1379, 149-163. doi: 10.1016/j.brainres.2010.10.099

Perovic, M., Tesic, V., Mladenovic Djordjevic, A., Smiljanic, K., LoncarevicVasiljkovic, N., Ruzdijic, S., et al. (2013). BDNF transcripts, proBDNF and proNGF, in the cortex and hippocampus throughout the life span of the rat. Age 35, 2057-2070. doi: 10.1007/s11357-012-9495-6

Petersen, S. L., Intlekofer, K. A., Moura-Conlon, P. J., Brewer, D. N., Del Pino Sans, J., and Lopez, J. A. (2013). Novel progesterone receptors: neural localization and possible functions. Front. Neurosci. 7:164. doi: 10.3389/fnins. 2013.00164

Pike, C. J., Carroll, J. C., Rosario, E. R., and Barron, A. M. (2009). Protective actions of sex steroid hormones in Alzheimer's disease. Front. Neuroendocrinol. 30, 239-258. doi: 10.1016/j.yfrne.2009.04.015

Promislow, D. E. L. (1991). Senescence in natural populations of mammals: a comparative study. Evolution 45, 1869-1887. doi: 10.1111/j.1558-5646.1991. tb02693.x

Psarra, A. M., and Sekeris, C. E. (2008). Steroid and thyroid hormone receptors in mitochondria. IUBMB Life 60, 210-223. doi: 10.1002/iub.37

Puche, J. E., García-Fernández, M., Muntané, J., Rioja, J., González-Barón, S., and Castilla Cortazar, I. (2008). Low doses of insulin-like growth factor-I induce mitochondrial protection in aging rats. Endocrinology 149, 2620-2627. doi: 10.1210/en.2007-1563

Rao, A. K., Dietrich, A. K., Ziegler, Y. S., and Nardulli, A. M. (2011). 17ß-Estradiolmediated increase in $\mathrm{Cu} / \mathrm{Zn}$ superoxide dismutase expression in the brain: a mechanism to protect neurons from ischemia. J. Steroid Biochem. Mol. Biol. 127, 382-389. doi: 10.1016/j.jsbmb.2011.06.008

Rasgon, N. L., Silverman, D., Siddarth, P., Miller, K., Ercoli, L. M., Elman, S., et al. (2005). Estrogen use and brain metabolic change in postmenopausal women. Neurobiol. Aging 26, 229-235. doi: 10.1016/j.neurobiolaging.2004.03.003

Regan, J. C., and Partridge, L. (2013). Gender and longevity: why do men die earlier than women? Comparative and experimental evidence. Best Pract. Res. Clin. Endocrinol. Metab. 27, 467-479. doi: 10.1016/j.beem.2013.05.016

Rekkas, P. V., Wilson, A. A., Lee, V. W., Yogalingam, P., Sacher, J., Rusjan, P., et al. (2014). Greater monoamine oxidase a binding in perimenopausal age as measured with carbon 11-labeled harmine positron emission tomography. JAMA Psychiatry 71, 873-879. doi: 10.1001/jamapsychiatry.2014.250

Rettberg, J. R., Yao, J., and Brinton, R. D. (2014). Estrogen: a master regulator of bioenergetic systems in the brain and body. Front. Neuroendocrinol. 35, 8-30. doi: 10.1016/j.yfrne.2013.08.001

Rey, P., Lopez-Real, A., Sanchez-Iglesias, S., Muñoz, A., Soto-Otero, R., and Labandeira-Garcia, J. L. (2007). Angiotensin type-1-receptor antagonists reduce 6-hydroxydopamine toxicity for dopaminergic neurons. Neurobiol. Aging 28, 555-567. doi: 10.1016/j.neurobiolaging.2006.02.018

Robertson, A. B., Klungland, A., Rognes, T., and Leiros, I. (2009). DNA repair in mammalian cells: base excision repair: the long and short of it. Cell. Mol. Life Sci. 66, 981-993. doi: 10.1007/s00018-009-8736-Z

Rocca, W. A., Bower, J. H., Maraganore, D. M., Ahlskog, J. E., Grossardt, B. R., de Andrade, M., et al. (2008). Increased risk of parkinsonism in women who underwent oophorectomy before menopause. Neurology 70, 200-209. doi: 10.1212/01.WNL.0000280573.30975.6a

Rodier, F., Coppe, J. P., Patil, C. K., Hoeijmakers, W. A., Muñoz, D. P., Raza, S. R., et al. (2009). Persistent DNA damage signalling triggers senescenceassociated inflammatory cytokine secretion. Nat. Cell Biol. 11, 973-979. doi: $10.1038 /$ ncb1909

Rodriguez-Pallares, J., Rey, P., Parga, J. A., Muñoz, A., Guerra, M. J., and Labandeira-Garcia, J. L. (2008). Brain angiotensin enhances dopaminergic cell 
death via microglial activation and NADPH-derived ROS. Neurobiol. Dis. 31, 58-73. doi: 10.1016/j.nbd.2008.03.003

Rodriguez-Perez, A. I., Valenzuela, R., Villar-Cheda, B., Guerra, M. J., Lanciego, J. L., and Labandeira-Garcia, J. L. (2010). Estrogen and angiotensin interaction in the substantia nigra. Relevance to postmenopausal Parkinson's disease. Exp. Neurol. 224, 517-526. doi: 10.1016/j.expneurol.2010.05.015

Rosario, E. R., Chang, L., Head, E. H., Stanczyk, F. Z., and Pike, C. J. (2011). Brain levels of sex steroid hormones in men and women during normal aging and in Alzheimer's disease. Neurobiol. Aging 32, 604-613. doi: 10.1016/j. neurobiolaging.2009.04.008

Rosario, E. R., Ramsden, M., and Pike, C. J. (2006). Progestins inhibit the neuroprotective effects of estrogen in rat hippocampus. Brain Res. 1099, 206-210. doi: 10.1016/j.brainres.2006.03.127

Rossetti, M. F., Cambiasso, M. J., Holschbach, M. A., and Cabrera, R. (2016). Oestrogens and progestagens: synthesis and action in the brain. J. Neuroendocrinol. 28:7. doi: 10.1111/jne.12402

Rossi, D., Brambilla, L., Valori, C. F., Roncoroni, C., Crugnola, A., Yokota, T., et al. (2008). Focal degeneration of astrocytes in amyotrophic lateral sclerosis. Cell Death Differ. 15, 1691-1700. doi: 10.1038/cdd.2008.99

Rutten, B. P., Schmitz, C., Gerlach, O. H., Oyen, H. M., de Mesquita, E. B., Steinbusch, H. W., et al. (2007). The aging brain: accumulation of DNA damage or neuron loss? Cell. Physiol. Biochem. 28, 91-98. doi: 10.1016/j.neurobiolaging. 2005.10.019

Salminen, A., Ojala, J., Kaarniranta, K., Haapasalo, A., Hiltunen, M., and Soininen, H. (2011). Astrocytes in the aging brain express characteristics of senescence-associated secretory phenotype. Eur. J. Neurosci. 34, 3-11. doi: 10.1111/j.1460-9568.2011.07738.x

Samarghandian, S., Azimi-Nezhad, M., and Farkhondeh, T. (2016). Preventive effect of carvacrol against oxidative damage in aged rat liver. Int. J. Vitam. Nutr. Res. doi: 10.1024/0300-9831/a000393 [Epub ahead of print].

Sanders, L. H., McCoy, J., Hu, X., Mastroberardino, P. G., Dickinson, B. C., Chang, C. J., et al. (2014). Mitochondrial DNA damage: molecular marker of vulnerable nigral neurons in Parkinson's disease. Neurobiol. Dis. 70, 214-223. doi: 10.1016/j.nbd.2014.06.014

Sarkey, S., Azcoitia, I., Garcia-Segura, L. M., Garcia-Ovejero, D., and DonCarlos, L. L. (2008). Classical androgen receptors in non-classical sites in the brain. Horm. Behav. 53, 753-764. doi: 10.1016/j.yhbeh.2008.02.015

Sárvári, M., Hrabovszky, E., Kallo, I., Solymosi, N., Likó, I., Berchtold, N., et al. (2012). Menopause leads to elevated expression of macrophageassociated genes in the aging frontal cortex: rat and human studies identify strikingly similar changes. J. Neuroinflammation 9:264. doi: 10.1186/1742-2094 $-9-264$

Sárvári, M., Hrabovszky, E., Kalló, I., Solymosi, N., Tóth, K., Likó, I., et al. (2011). Estrogens regulate neuroinflammatory genes via estrogen receptors $\alpha$ and $\beta$ in the frontal cortex of middle-aged female rats. J. Neuroinflammation 8:82. doi: 10.1186/1742-2094-8-82

Sárvári, M., Kalló, I., Hrabovszky, E., Solymosi, N., and Liposits, Z. (2014). Ovariectomy and subsequent treatment with estrogen receptor agonists tune the innate immune system of the hippocampus in middle-aged female rats. PLoS One 9:e88540. doi: 10.1371/journal.pone.0088540

Saunders-Pullman, R., Gordon-Elliott, J., Parides, M., Fahn, S., Saunders, H. R., and Bressman, S. (1999). The effect of estrogen replacement on early Parkinson's disease. Neurology 52, 1417-1421. doi: 10.1212/WNL.52.7.1417

Scarpulla, R. C. (2008). Transcriptional paradigms in mammalian mitochondrial biogenesis and function. Physiol. Rev. 88, 611-638. doi: 10.1152/physrev.00025. 2007

Scharfman, H. E., and MacLusky, N. J. (2006). Estrogen and brain-derived neurotrophic factor (BDNF) in hippocampus: complexity of steroid hormonegrowth factor interactions in the adult CNS. Front. Neuroendocrinol. 27, 415-435. doi: 10.1016/j.yfrne.2006.09.004

Schiewer, M. J., and Knudsen, K. E. (2016). Linking DNA damage and hormone signaling pathways in cancer. Trends Endocrinol. Metab. 27, 216-225. doi: 10.1016/j.tem.2016.02.004

Schiöth, H. B., Craft, S., Brooks, S. J., Frey, W. H. II., and Benedict, C. (2012). Brain insulin signaling and Alzheimer's disease: current evidence and future directions. Mol. Neurobiol. 46, 4-10. doi: 10.1007/s12035-011-8229-6

Schipper, H. M. (1996). Astrocytes, brain aging, and neurodegeneration. Neurobiol. Aging 17, 467-480. doi: 10.1016/0197-4580(96)00014-0
Schroots, J. J. F., FernáNdez Ballesteros, R. O., and Rudinger, G. (1999). Aging in Europe. Amsterdam; Washington, DC: IOS Press.

Scott, E., Zhang, Q. G., Wang, R., Vadlamudi, R., and Brann, D. (2012). Estrogen neuroprotection and the critical period hypothesis. Front. Neuroendocrinol. 33, 85-104. doi: 10.1016/j.yfrne.2011.10.001

Selvamani, A., Sathyan, P., Miranda, R. C., and Sohrabji, F. (2012). An antagomir to microRNA Let7f promotes neuroprotection in an ischemic stroke model. PLoS One 7:e32662. doi: 10.1371/journal.pone.0032662

Selvaraj, V., Stocco, D. M., and Tu, L. N. (2015). Minireview: translocator protein (TSPO) and steroidogenesis: a reappraisal. Mol. Endocrinol. 29, 490-501. doi: 10.1210/me.2015-1033

Shadyab, A. H., Macera, C. A., Shaffer, R. A., Jain, S., Gallo, L. C., Gass, M. L., et al. (2017). Ages at menarche and menopause and reproductive lifespan as predictors of exceptional longevity in women: the Women's Health Initiative. Menopause 24, 35-44. doi: 10.1097/GME.0000000000000710

Shao, C., Xiong, S., Li, G. M., Gu, L., Mao, G., Markesbery, W. R., et al. (2008). Altered 8-oxoguanine glycosylase in mild cognitive impairment and late-stage Alzheimer's disease brain. Free Radic. Biol. Med. 45, 813-819. doi: 10.1016/j. freeradbiomed.2008.06.003

Shi, C., Zou, J., Li, G., Ge, Z., Yao, Z., and Xu, J. (2011). Bilobalide protects mitochondrial function in ovariectomized rats by up-regulation of mRNA and protein expression of cytochrome c oxidase subunit I. J. Mol. Neurosci. 45, 69-75. doi: 10.1007/s12031-010-9388-z

Shibutani, S., Takeshita, M., and Grollman, A. P. (1991). Insertion of specific bases during DNA synthesis past the oxidation-damaged base 8-oxodG. Nature 349, 431-434. doi: 10.1038/349431a0

Shimada, H., Makizako, H., Doi, T., Yoshida, D., Tsutsumimoto, K., Anan, Y., et al. (2014). A large, cross-sectional observational study of serum BDNF, cognitive function, and mild cognitive impairment in the elderly. Front. Aging Neurosci. 6:69. doi: 10.3389/fnagi.2014.00069

Siani, F., Greco, R., Levandis, G., Ghezzi, C., Daviddi, F., Demartini, C., et al. (2017). Influence of estrogen modulation on glia activation in a murine model of Parkinson's disease. Front. Neurosci. 11:306. doi: 10.3389/fnins.2017.00306

Simpkins, J. W., Yang, S. H., Sarkar, S. N., and Pearce, V. (2008). Estrogen actions on mitochondria-physiological and pathological implications. Mol. Cell. Endocrinol. 290, 51-59. doi: 10.1016/j.mce.2008.04.013

Singh, M., Meyer, E. M., and Simpkins, J. W. (1995). The effect of ovariectomy and estradiol replacement on brain-derived neurotrophic factor messenger ribonucleic acid expression in cortical and hippocampal brain regions of female Sprague-Dawley rats. Endocrinology 136, 2320-2324. doi: 10.1210/en.136. 5.2320

Singh, M., and Su, C. (2013). Progesterone and neuroprotection. Horm. Behav. 63, 284-290. doi: 10.1016/j.yhbeh.2012.06.003

Sohrabji, F. (2015). Estrogen-IGF-1 interactions in neuroprotection: ischemic stroke as a case study. Front. Neuroendocrinol. 36, 1-14. doi: 10.1016/j.yfrne. 2014.05.003

Sohrabji, F., Miranda, R. C., and Toran-Allerand, C. D. (1995). Identification of a putative estrogen response element in the gene encoding brainderived neurotrophic factor. Proc. Natl. Acad. Sci. U S A 92, 11110-11114. doi: 10.1073/pnas.92.24.11110

Son, S. W., Lee, J. S., Kim, H. G., Kim, D. W., Ahn, Y. C., and Son, C. G. (2016). Testosterone depletion increases the susceptibility of brain tissue to oxidative damage in a restraint stress mouse model. J. Neurochem. 136, 106-117. doi: $10.1111 /$ jnc. 13371

Sorwell, K. G., Kohama, S. G., and Urbanski, H. F. (2012). Perimenopausal regulation of steroidogenesis in the nonhuman primate. Neurobiol. Aging 33, 1487.e1-1487.e13. doi: 10.1016/j.neurobiolaging.2011.05.004

Stirone, C., Duckles, S. P., and Krause, D. N. (2003). Multiple forms of estrogen receptor- $\alpha$ in cerebral blood vessels: regulation by estrogen. Am. J. Physiol. Endocrinol. Metab. 284, E184-E192. doi: 10.1152/ajpendo.00165.2002

Sugasawa, K. (2011). Multiple DNA damage recognition factors involved in mammalian nucleotide excision repair. Biochemistry (Mosc) 76, 16-23. doi: $10.1134 / \mathrm{s} 0006297911010044$

Suzuki, S., Brown, C. M., and Wise, P. M. (2009). Neuroprotective effects of estrogens following ischemic stroke. Front. Neuroendocrinol. 30, 201-211. doi: 10.1016/j.yfrne.2009.04.007

Suzuki, T., Masuda, M., Friesen, M. D., and Ohshima, H. (2001). Formation of spiroiminodihydantoin nucleoside by reaction of 8-oxo-7,8-dihydro- $2^{\prime}$ - 
deoxyguanosine with hypochlorous acid or a myeloperoxidase- $\mathrm{H}_{2} \mathrm{O}_{2}-\mathrm{Cl}^{-}$ system. Chem. Res. Toxicol. 14, 1163-1169. doi: 10.1021/tx010024z

Swain, U., and Subba Rao, K. (2011). Study of DNA damage via the comet assay and base excision repair activities in rat brain neurons and astrocytes during aging. Mech. Ageing Dev. 132, 374-381. doi: 10.1016/j.mad.2011. 04.012

Sykora, P., Yang, J. L., Ferrarelli, L. K., Tian, J., Tadokoro, T., Kulkarni, A., et al. (2013). Modulation of DNA base excision repair during neuronal differentiation. Neurobiol. Aging 34, 1717-1727. doi: 10.1016/j.neurobiolaging. 2012.12.016

Szymczak, S., Kalita, K., Jaworski, J., Mioduszewska, B., Savonenko, A., Markowska, A., et al. (2006). Increased estrogen receptor $\beta$ expression correlates with decreased spine formation in the rat hippocampus. Hippocampus 16, 453-463. doi: 10.1002/hipo.20172

Tang, M. X., Jacobs, D., Stern, Y., Marder, K., Schofield, P., Gurland, B., et al. (1996). Effect of oestrogen during menopause on risk and age at onset of Alzheimer's disease. Lancet 348, 429-432. doi: 10.1016/s0140-6736(96) 03356-9

Torika, N., Asraf, K., Roasso, E., Danon, A., and Fleisher-Berkovich, S. (2016). Angiotensin converting enzyme inhibitors ameliorate brain inflammation associated with microglial activation: possible implications for Alzheimer's disease. J. Neuroimmune. Pharmacol. 11, 774-785. doi: 10.1007/s11481-0169703-8

Toro-Urrego, N., Garcia-Segura, L. M., Echeverria, V., and Barreto, G. E. (2016). Testosterone protects mitochondrial function and regulates neuroglobin expression in astrocytic cells exposed to glucose deprivation. Front. Aging Neurosci. 8:152. doi: 10.3389/fnagi.2016.00152

Tsutsui, K., Ukena, K., Sakamoto, H., Okuyama, S., and Haraguchi, S. (2011). Biosynthesis, mode of action, and functional significance of neurosteroids in the purkinje cell. Front. Endocrinol. 2:61. doi: 10.3389/fendo.2011.00061

Unger, J. W. (1998). Glial reaction in aging and Alzheimer's disease. Microsc. Res. Tech. 43, 24-28. doi: 10.1002/(SICI)1097-0029(19981001)43:1<24::AIDJEMT4>3.0.CO;2-P

Urbanska, K., Pannizzo, P., Lassak, A., Gualco, E., Surmacz, E., Croul, S., et al. (2009). Estrogen receptor $\beta$-mediated nuclear interaction between IRS-1 and Rad51 inhibits homologous recombination directed DNA repair in medulloblastoma. J. Cell. Physiol. 219, 392-401. doi: 10.1002/jcp.21683

Vagnerova, K., Liu, K., Ardeshiri, A., Cheng, J., Murphy, S. J., Hurn, P. D., et al. (2010). Poly (ADP-ribose) polymerase-1 initiated neuronal cell death pathway-do androgens matter? Neuroscience 166, 476-481. doi: 10.1016/j. neuroscience.2009.12.041

Veiga, S., Melcangi, R. C., Doncarlos, L. L., Garcia-Segura, L. M., and Azcoitia, I. (2004). Sex hormones and brain aging. Exp. Gerontol. 39, 1623-1631. doi: 10.1016/j.exger.2004.05.008

Velarde, M. C. (2014). Mitochondrial and sex steroid hormone crosstalk during aging. Longev. Healthspan 3:2. doi: 10.1186/2046-2395-3-2

Verkhratsky, A., Rodriguez, J. J., and Parpura, V. (2014). Neuroglia in ageing and disease. Cell Tissue Res. 357, 493-503. doi: 10.1007/s00441-014-1814-z

Vermulst, M., Bielas, J. H., Kujoth, G. C., Ladiges, W. C., Rabinovitch, P. S., Prolla, T. A., et al. (2007). Mitochondrial point mutations do not limit the natural lifespan of mice. Nat. Genet. 39, 540-543. doi: 10.1038/ng1988

Villa, A., Vegeto, E., Poletti, A., and Maggi, A. (2016). Estrogens, neuroinflammation, and neurodegeneration. Endocr. Rev. 37, 372-402. doi: 10.1210/er.2016-1007

Virbasius, J. V., and Scarpulla, R. C. (1994). Activation of the human mitochondrial transcription factor A gene by nuclear respiratory factors: a potential regulatory link between nuclear and mitochondrial gene expression in organelle biogenesis. Proc. Natl. Acad. Sci. U S A 91, 1309-1313. doi: 10.1073/pnas.91.4.1309

von Bernhardi, R., Eugenín-von Bernhardi, L., and Eugenin, J. (2015). Microglial cell dysregulation in brain aging and neurodegeneration. Front. Aging Neurosci. 7:124. doi: 10.3389 /fnagi.2015.00124

Wang, J., Markesbery, W. R., and Lovell, M. A. (2006). Increased oxidative damage in nuclear and mitochondrial DNA in mild cognitive impairment. J. Neurochem. 96, 825-832. doi: 10.1111/j.1471-4159.2005.03615.x

Wang, J., Xiong, S., Xie, C., Markesbery, W. R., and Lovell, M. A. (2005). Increased oxidative damage in nuclear and mitochondrial DNA in Alzheimer's disease. J. Neurochem. 93, 953-962. doi: 10.1111/j.1471-4159.2005.03053.x
Waters, E. M., Mitterling, K., Spencer, J. L., Mazid, S., McEwen, B. S., and Milner, T. A. (2009). Estrogen receptor $\alpha$ and $\beta$ specific agonists regulate expression of synaptic proteins in rat hippocampus. Brain Res. 1290, 1-11. doi: 10.1016/j.brainres.2009.06.090

Waters, E. M., Yildirim, M., Janssen, W. G., Lou, W. Y., McEwen, B. S., Morrison, J. H., et al. (2011). Estrogen and aging affect the synaptic distribution of estrogen receptor $\beta$-immunoreactivity in the CA1 region of female rat hippocampus. Brain Res. 1379, 86-97. doi: 10.1016/j.brainres.2010.09.069

Wei, S. M., Baller, E. B., Kohn, P. D., Kippenhan, J. S., Kolachana, B., Soldin, S. J., et al. (2017). Brain-derived neurotrophic factor Val66Met genotype and ovarian steroids interactively modulate working memory-related hippocampal function in women: a multimodal neuroimaging study. Mol. Psychiatry doi: 10.1038/mp.2017.72 [Epub ahead of print].

Weissman, L., de Souza-Pinto, N. C., Stevnsner, T., and Bohr, V. A. (2007a). DNA repair, mitochondria, and neurodegeneration. Neuroscience 145, 1318-1329. doi: $10.1016 /$ j.neuroscience.2006.08.061

Weissman, L., Jo, D. G., Sørensen, M. M., de Souza-Pinto, N. C., Markesbery, W. R., Mattson, M. P., et al. (2007b). Defective DNA base excision repair in brain from individuals with Alzheimer's disease and amnestic mild cognitive impairment. Nucleic Acids Res. 35, 5545-5555. doi: 10.1093/nar/gkm605

Williams, J. S., Lujan, S. A., and Kunkel, T. A. (2016). Processing ribonucleotides incorporated during eukaryotic DNA replication. Nat. Rev. Mol. Cell Biol. 17, 350-363. doi: 10.1038/nrm.2016.37

Witty, C. F., Gardella, L. P., Perez, M. C., and Daniel, J. M. (2013). Short-term estradiol administration in aging ovariectomized rats provides lasting benefits for memory and the hippocampus: a role for insulin-like growth factor-I. Endocrinology 154, 842-852. doi: 10.1210/en.2012-1698

Woolley, C. S., and McEwen, B. S. (1992). Estradiol mediates fluctuation in hippocampal synapse density during the estrous cycle in the adult rat. J. Neurosci. 12, 2549-2554.

Woolley, C. S., and McEwen, B. S. (1993). Roles of estradiol and progesterone in regulation of hippocampal dendritic spine density during the estrous cycle in the rat. J. Comp. Neurol. 336, 293-306. doi: 10.1002/cne.9033 60210

World Health Statistics. (2017). Mental Health of Older Adults. Available online at: www.who.int/mediacentre/factsheets/fs381/en/

Yang, J. L., Lin, Y. T., Chuang, P. C., Bohr, V. A., and Mattson, M. P. (2014). BDNF and exercise enhance neuronal DNA repair by stimulating CREB-mediated production of apurinic/apyrimidinic endonuclease 1. Neuromolecular Med. 16, 161-174. doi: 10.1007/s12017-013-8270-x

Yang, S. H., Liu, R., Perez, E. J., Wen, Y., Stevens, S. M. Jr., Valencia, T., et al. (2004). Mitochondrial localization of estrogen receptor B. Proc. Natl. Acad. Sci. U S A 101, 4130-4135. doi: 10.1073/pnas.0306948101

Yao, J., Chen, S., Cadenas, E., and Brinton, R. D. (2011). Estrogen protection against mitochondrial toxin-induced cell death in hippocampal neurons: antagonism by progesterone. Brain Res. 1379, 2-10. doi: 10.1016/j.brainres. 2010.11.090

Yao, J., Hamilton, R. T., Cadenas, E., and Brinton, R. D. (2010). Decline in mitochondrial bioenergetics and shift to ketogenic profile in brain during reproductive senescence. Biochim. Biophys. Acta 1800, 1121-1126. doi: 10.1016/j.bbagen.2010.06.002

Yao, J., Irwin, R., Chen, S., Hamilton, R., Cadenas, E., and Brinton, R. D. (2012). Ovarian hormone loss induces bioenergetic deficits and mitochondrial $\beta$ amyloid. Neurobiol. Aging 33, 1507-1521. doi: 10.1016/j.neurobiolaging.2011. 03.001

Yao, J., Irwin, R. W., Zhao, L., Nilsen, J., Hamilton, R. T., and Brinton, R. D. (2009). Mitochondrial bioenergetic deficit precedes Alzheimer's pathology in female mouse model of Alzheimer's disease. Proc. Natl. Acad. Sci. U S A 106, 14670-14675. doi: 10.1073/pnas.0903563106

Yao, J., Zhao, L., Mao, Z., Chen, S., Wong, K. C., To, J., et al. (2013). Potentiation of brain mitochondrial function by S-equol and R/S-equol estrogen receptor $\beta$-selective phytoSERM treatments. Brain Res. 1514, 128-141. doi: 10.1016/j. brainres.2013.02.021

Yin, F., Yao, J., Sancheti, H., Feng, T., Melcangi, R. C., Morgan, T. E., et al. (2015). The perimenopausal aging transition in the female rat brain: decline in bioenergetic systems and synaptic plasticity. Neurobiol. Aging 36, 2282-2295. doi: 10.1016/j.neurobiolaging.2015.03.013 
Young, L. J., and Pfaff, D. W. (2014). Sex differences in neurological and psychiatric disorders. Front. Neuroendocrinol. 35, 253-254. doi: 10.1016/j. yfrne.2014.05.005

Yu, Y., Cui, Y., Niedernhofer, L. J., and Wang, Y. (2016). Occurrence, biological consequences, and human health relevance of oxidative stress-induced DNA damage. Chem. Res. Toxicol. 29, 2008-2039. doi: 10.1021/acs.chemrestox. $6 \mathrm{~b} 00265$

Yu, P., Li, S., Zhang, Z., Wen, X., Quan, W., Tian, Q., et al. (2017). Progesteronemediated angiogenic activity of endothelial progenitor cell and angiogenesis in traumatic brain injury rats were antagonized by progesterone receptor antagonist. Cell Prolif. 50:e12362. doi: 10.1111/cpr.12362

Yue, X., Lu, M., Lancaster, T., Cao, P., Honda, S., Staufenbiel, M., et al. (2005). Brain estrogen deficiency accelerates $\mathrm{A} \beta$ plaque formation in an Alzheimer's disease animal model. Proc. Natl. Acad. Sci. U S A 102, 19198-19203. doi: 10.1073/pnas.0505203102

Zagni, E., Simoni, L., and Colombo, D. (2016). Sex and gender differences in central nervous system-related disorders. Neurosci. J. 2016:2827090. doi: $10.1155 / 2016 / 2827090$

Zárate, S., Astiz, M., Magnani, N., Imsen, M., Merino, F., Álvarez, S., et al. (2017). Hormone deprivation alters mitochondrial function and lipid profile in the hippocampus. J. Endocrinol. 233, 1-14. doi: 10.1530/JOE-16-0451

Zárate, S., and Seilicovich, A. (2010). Estrogen receptors and signaling pathways in lactotropes and somatotropes. Neuroendocrinology 92, 215-223. doi: $10.1159 / 000321683$
Zaremba, T., Thomas, H. D., Cole, M., Coulthard, S. A., Plummer, E. R., and Curtin, N. J. (2011). Poly(ADP-ribose) polymerase-1 (PARP-1) pharmacogenetics, activity and expression analysis in cancer patients and healthy volunteers. Biochem. J. 436, 671-679. doi: 10.1042/BJ20101723

Zhao, Y., He, L., Zhang, Y., Zhao, J., Liu, Z., Xing, F., et al. (2017). Estrogen receptor $\alpha$ and $\beta$ regulate actin polymerization and spatial memory through an SRC-1/mTORC2-dependent pathway in the hippocampus of female mice. J. Steroid Biochem. Mol. Biol. 174, 96-113. doi: 10.1016/j.jsbmb.2017. 08.003

Zhu, C., Wang, S., Wang, B., Du, F., Hu, C., Li, H., et al. (2015). 17ß-Estradiol up-regulates Nrf2 via PI3K/AKT and estrogen receptor signaling pathways to suppress light-induced degeneration in rat retina. Neuroscience 304, 328-339. doi: 10.1016/j.neuroscience.2015.07.057

Conflict of Interest Statement: The authors declare that the research was conducted in the absence of any commercial or financial relationships that could be construed as a potential conflict of interest.

Copyright (c) 2017 Zárate, Stevnsner and Gredilla. This is an open-access article distributed under the terms of the Creative Commons Attribution License (CC BY). The use, distribution or reproduction in other forums is permitted, provided the original author(s) or licensor are credited and that the original publication in this journal is cited, in accordance with accepted academic practice. No use, distribution or reproduction is permitted which does not comply with these terms. 